\title{
COMPARISON OF MOLECULAR-WIRES FOR ENHANCING CHARGE TRANSPORT OF ENZYMATIC ELECTRODE ASSEMBLIES: A GLYCEROL BIOANODE MODEL
}

\author{
A Thesis \\ by \\ AISHWARYA MAHADEVAN
Submitted to the Office of Graduate and Professional Studies of Texas A\&M University
in partial fulfillment of the requirements for the degree of \\ MASTER OF SCIENCE
}

\begin{abstract}
Chair of Committee, Sandun Fernando
Committee Members, Raghupathy Karthikeyan

Mike McShane

Head of Department, $\quad$ Stephen Searcy
\end{abstract}

December 2014

Major Subject: Biological and Agricultural Engineering

Copyright 2014 Aishwarya Mahadevan 


\begin{abstract}
Biomolecules are inherently less conductive. Therefore, bio-electronic devices that depend on conventional biomolecules to tether enzymes onto electrode supports and to shuttle electrons between the enzyme and the electrode suffer from charge dissipation. This results in bioanondes with decreased current-voltage responses as a result of ohmic losses. Reducing the internal resistance is the simplest way of increasing the currentvoltage response associated with bioanodes and has yet been an unmet challenge. A novel iron (II) sulfide (FeS) based molecular wiring system was developed for immobilizing glycerol dehydrogenase on a gold electrode surface. Amperometric and potentiometric analyses with glycerol dehydrogenase-based model electrodes confirmed the ability of this single-molecule to remarkably amplify, about ten-fold increase in current and up to $24 \%$ increase in voltage outputs, as compared to electrodes fabricated with the conventional Pyrroloquinoline quinone-based composite molecular wiring system. FeS achieves the dual purpose of anchoring the enzyme to the gold electrode while also mediating electron shuttling between coenzyme and the electrode surface. This dual functionality allows usage of a single-molecular wire to foster electrical communication between the enzyme and the electrode instead of the conventional multi-molecular wiring system and in turn reducing the internal resistance of the electrode. The resulting increase in current/voltage response opens up a wide range of possibilities for developing efficient bio-electrodes for bioelectronics applications.
\end{abstract}




\section{ACKNOWLEDGEMENTS}

First and foremost I wish to express my sincere gratitude to my advisor, Dr. Sandun Fernando for the continuous support of my Master's study and research, for his patience, motivation, enthusiasm, and immense knowledge. His guidance helped me in all the time of research and writing of this thesis. I could not have imagined having a better advisor and mentor for my Master's study.

I would like to thank my thesis committee: Dr. Raghupathy Karthikeyan and Dr. Mike McShane, for their guidance, encouragement and insightful comments. I sincerely thank Dr. Karthi again for providing me space in his lab for almost a year during the construction time.

A special thanks to Duminda for being awe-spiring and teaching me the fundamentals of this research, always having time to answer my questions and clarify doubts. I also thank my lab mates in the Nanoscale Biological Engineering Lab and Lab-108 for helping me learn various lab instruments and associated software tools. I extend my gratitude to my fellow graduate students, the BAEN faculty and staff for making my time at Texas A\&M University a great experience. I would also like to thank Diana Vanegas from University of Florida for sharing her valuable knowledge on sensing techniques. 
A big thank you to my parents Mahadevan and Sumathi for the love, support, and constant encouragement throughout the years. Thanks to all my family and friends for the good wishes, prayers and blessings. A special thank you to Sneha, Shefali and Shobhit, for their support throughout this eventful journey. 


\section{TABLE OF CONTENTS}

Page

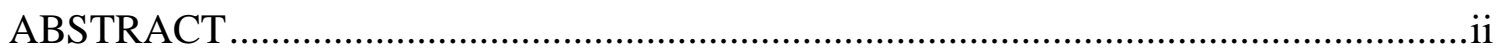

ACKNOWLEDGEMENTS ..................................................................................ii

LIST OF FIGURES …................................................................................... vii

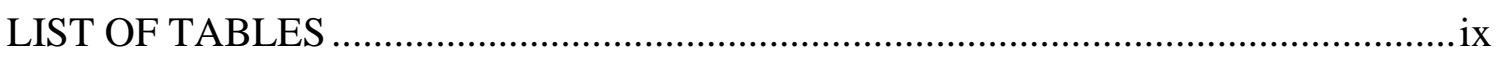

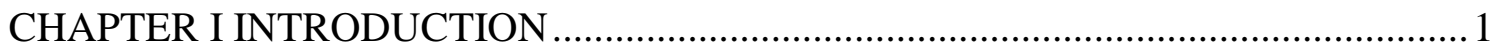

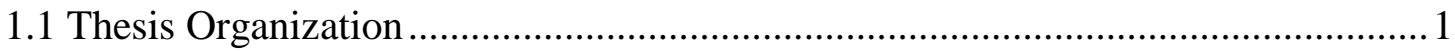

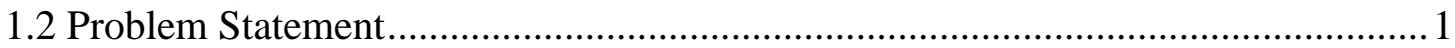

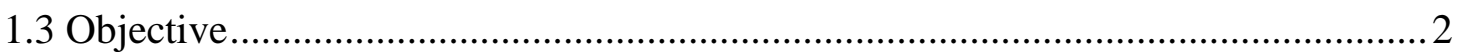

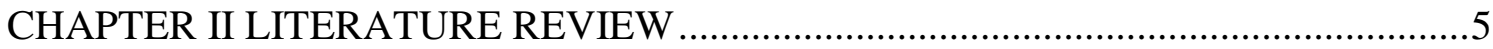

CHAPTER III CONVENTIONAL PQQ-BASED GLYCEROL SELECTIVE

BIOANODE - POTENTIOMETRY VS AMPEROMETRY MODE............................

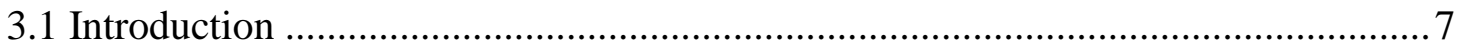

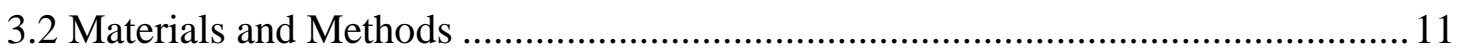

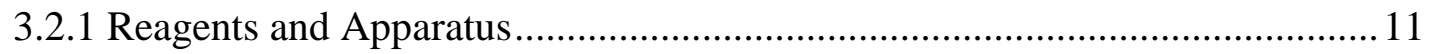

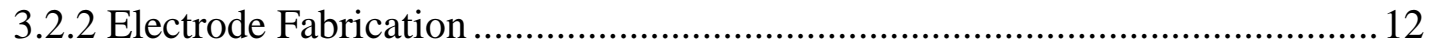

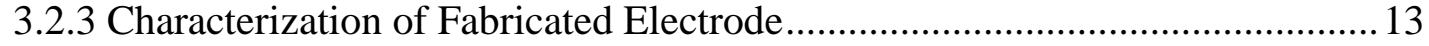

3.2.4 Potentiometric Analysis ............................................................................. 14

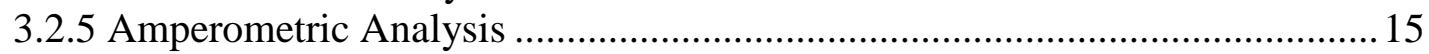

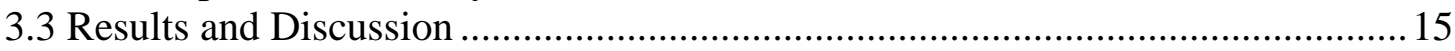

3.3.1 Verification of SAM Formation via Electrochemical Analyses ..................... 15

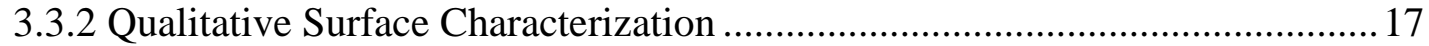

3.3.3 Current-Voltage Behavior of the Reagents ................................................... 19

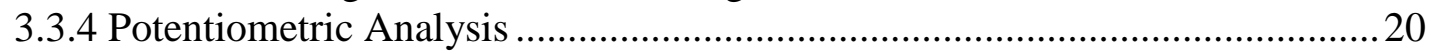

3.3.5 Amperometric Response of the Enzymatic Electrode ................................ 23

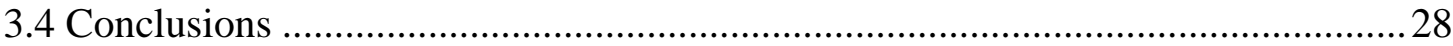

CHAPTER IV A NOVEL IRON-SULFIDE BASED MOLECULAR-WIRE FOR

ENHANCING CHARGE TRANSPORT OF GLYCEROL SELECTIVE 
BIOANODE - A COMPARISON WITH THE PQQ-BASED CONVENTIONAL

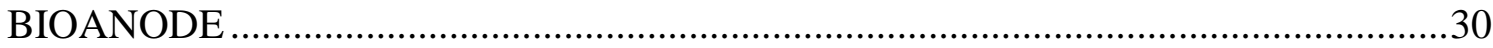

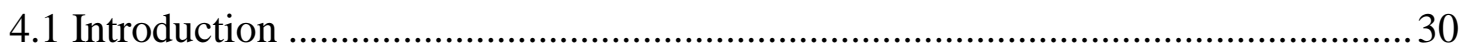

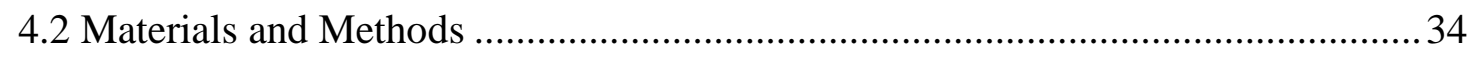

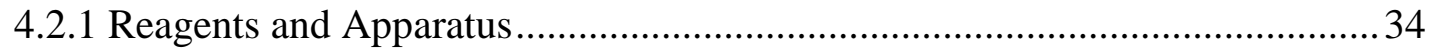

4.2.2 Electrode Fabrication .................................................................................. 35

4.2.3 Characterization of Fabricated Electrode........................................................... 35

4.2.4 Potentiometric and Amperometric Analyses ................................................... 35

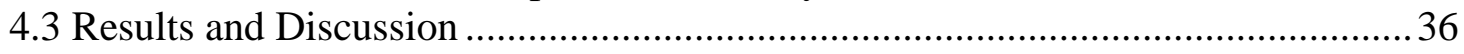

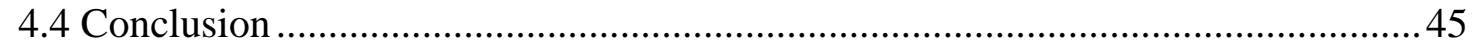

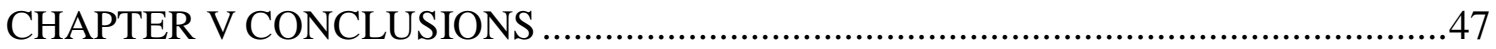

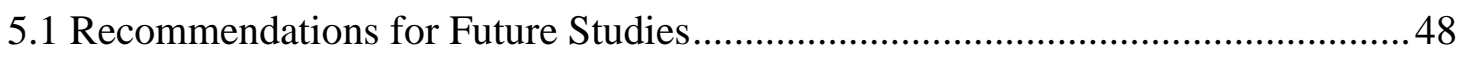

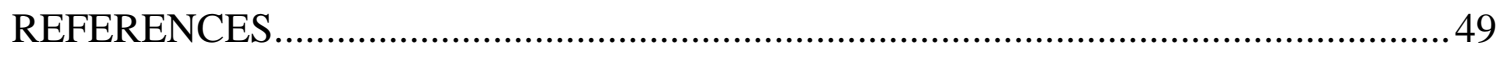

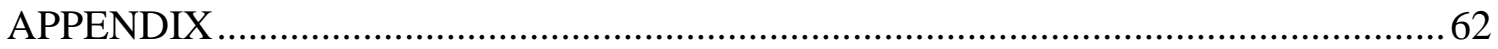




\section{LIST OF FIGURES}

Page

Figure 1. Wiring scheme for the GIDH based enzymatic anode 10

Figure 2. Cyclic voltammograms of bare Au electrode (green) and modified $\mathrm{Au}$ electrode after formation of each SAM layer, conducted in $0.01 \mathrm{M}$ potassium ferricyanide with $0.1 \mathrm{M} \mathrm{KNO}_{3}$ as the supporting electrolyte at a potential scan rate of $50 \mathrm{mV} / \mathrm{s}$

Figure 3. SEM images: (A) Bare Au electrode, (B) Enzyme Attached Au electrode...... 18

Figure 4. (A \& B) Cyclic voltammograms of individual reagent species used.

Scan rate is $50 \mathrm{mV} / \mathrm{s}$

Figure 5. The instantaneous OCV for different glycerol concentrations in WS solution obtained with the conventional 3-electrode system.

Figure 6. Equilibrated OCV response (10 min after reaction initiation) for glycerol concentrations ranging from $0.001-1 \mathrm{M}$ in the Two-electrode system; $\mathrm{W}$ (Water), WS (Water + Enzyme Stimulants), EE (Enzymatic Electrode).

Figure 7. Cyclic voltammograms for enzyme electrode and control (Bare Au) with and without glycerol diluted with water containing enzyme stimulants (WS). Scan rate is $50 \mathrm{mV} / \mathrm{s}$.

Figure 8. Cyclic voltammograms for enzyme electrode in increasing concentrations of glycerol $(\mathrm{a}-0 \mathrm{M}, \mathrm{b}-0.001 \mathrm{M}, \mathrm{c}-0.01 \mathrm{M}, \mathrm{d}-0.1 \mathrm{M}$ and e - $1 \mathrm{M})$ diluted with WS solution. Scan rate is $50 \mathrm{mV} / \mathrm{s}$.

Figure 9. Peak current (Ip) at $1.3 \mathrm{~V}$ and $0.665 \mathrm{~V}$ vs. glycerol concentrations measured by enzymatic electrode (EE) using $\mathrm{CV}$ scans between 0 to $1.5 \mathrm{~V} \ldots 25$

Figure 10. Chronoamperograms for PQQ-based enzyme electrode in $0.001-1 \mathrm{M}$ glycerol

Figure 11. Cottrell plot ( $\mathrm{I} \mathrm{vs} \mathrm{t}^{-1 / 2}$ ) obtained from chronoamperograms of PQQbased enzyme electrode in $0.001-1 \mathrm{M}$ glycerol.

Figure 12. Correlation of bulk concentration and diffusion coefficient. Initial $\mathrm{E}=0.665 \mathrm{~V}$ and Final $\mathrm{E}=1.3 \mathrm{~V}$ for this study....................................28

Figure 13. Response mechanism of conventional PQQ-based enzyme electrode 32 
Figure 14. Wiring scheme and response mechanism of the Fe-S-based enzyme electrode

Figure 15. Cyclic voltammograms of bare Au electrode (yellow) and modified $\mathrm{Au}$ electrode after formation of each SAM layer, conducted in $0.01 \mathrm{M}$ potassium ferricyanide with $0.1 \mathrm{M} \mathrm{KNO}_{3}$ as the supporting electrolyte at a potential scan rate of $50 \mathrm{mV} / \mathrm{s}$.

Figure 16. The instantaneous OCV obtained by FeS-based and PQQ-based enzyme electrodes in aqueous glycerol concentrations $0.001-1 \mathrm{M}$ containing enzyme stimulants.

Figure 17. Cyclic voltammograms for FeS-based enzyme electrode in increasing concentrations of glycerol $(\mathrm{a}-0 \mathrm{M}, \mathrm{b}-0.001 \mathrm{M}, \mathrm{c}-0.01 \mathrm{M}, \mathrm{d}-0.1 \mathrm{M}$ and $\mathrm{e}-1 \mathrm{M})$ at scan rate $50 \mathrm{mV} / \mathrm{s}$.

Figure 18. Peak current (Ip) at $1.3 \mathrm{~V}$ and $0.665 \mathrm{~V}$ vs. glycerol concentrations measured by enzymatic electrodes (FeS-based and PQQ-based) derived from $\mathrm{CV}$ scans between 0 to $1.5 \mathrm{~V}$ at scan rate $50 \mathrm{mV} / \mathrm{s}$.

Figure 19. Equilibrated (60 s) constant potential amperometric measurements of anodic currents for FeS-based and PQQ-based enzyme electrodes in glycerol concentrations between $0.001-1 \mathrm{M}$ at $\mathrm{E}=1.3 \mathrm{~V}$

Figure 20. Chronoamperograms for FeS-based enzyme electrode in $0.001-1 \mathrm{M}$ glycerol

Figure 21. Cottrell plot (I vs t ${ }^{-1 / 2}$ ) obtained from chronoamperograms of FeSbased enzyme electrode in $0.001-1 \mathrm{M}$ glycerol

Figure 22. Correlation of bulk concentration and diffusion coefficient. Initial $\mathrm{E}=0.665 \mathrm{~V}$ and Final $\mathrm{E}=1.3 \mathrm{~V}$ for this study. 


\section{LIST OF TABLES}

Table 1. Peak current and half potentials of reagent species obtained from CV ........... 19

Table 2. Percentage increase in current and voltage generated by different methods ..... 42 


\section{CHAPTER I}

\section{INTRODUCTION}

\subsection{Thesis Organization}

This thesis consists of five chapters. Chapter I (this chapter) is a generalized introduction of the research problem, the overall objective, specific objectives and respective tasks. A detailed literature review of biochemical and electrochemical perspectives of a bioanode is presented in Chapter II. Chapter III reports the findings of specific objective 1, i.e. the construction of a PQQ-based glycerol selective bioanode and its current-voltage responses to glycerol. Chapter IV presents the findings of specific objective 2, i.e. construction of a FeS-based glycerol selective bioanode and its current-voltage responses to glycerol. This chapter also compares and discusses the current-voltage responses achieved by both the molecular wiring systems, i.e. findings of specific objective 3. Chapter $\mathrm{V}$ presents recommendations for future work.

\subsection{Problem Statement}

A fundamental requirement for a bioanode (that consists of oxidoreductases or redox enzymes) to be effective for applications in bioelectronics (i.e. biosensors and biofuel cells) is its ability to be a good electrical conductor. However, immobilization of such enzymes on the electrode surface using a large number of interfacing molecules and crosslinking polymers hampers the effectiveness of electron transport, resulting in bioanodes with low electrical performance (i.e., current-voltage-power output). Therefore, there is a 
need for an effective molecular wiring system that can allow unimpeded charge transport from the enzyme to the electrode support.

\subsection{Objective}

The overarching objective of this project was to develop and compare the electrochemical response and charge transport characteristics of enzymatic electrodes after direct attachment of glycerol-dehydrogenase/nicotinamide-adenine-dinucleotide (GIDH-NAD $\left.{ }^{+}\right)$ apoenzyme-coenzyme complex to a supporting gold electrode using a novel inorganic iron (II) sulfide (FeS)-based single-molecular-wire and a conventional pyrroloquinoline quinone (PQQ) based composite wiring system.

Central Hypothesis: Our hypothesis is that the [FeS] complex based electrode system will yield a better current/voltage response to varying glycerol concentrations as opposed to an electrode formed with the conventional PQQ-based wiring system.

This hypothesis will be tested via the following specific objectives:

Specific Objective 1: To evaluate the effectiveness of tethering the GIDH-NAD ${ }^{+}$complex onto a gold electrode via PQQ-mediated wiring system.

This aim of this study was to ascertain whether it is feasible to use the conventional PQQbased molecular wiring to successfully attach redox center of enzyme GIDH to the $\mathrm{Au}$ electrode surface the way it has been used for attaching other oxidoreductases to gold 
electrode surface and to evaluate the electrical performance of this bio-electrode. The specific objective will be tested by performing the following tasks:

Task 1 - Electrode fabrication - to yield a PQQ-mediated GIDH electrode.

Task 2 - Electrode characterization - to confirm the formation of self-assembled monolayers (SAMs) and immobilization of enzyme GIDH on the gold electrode surface.

Task 3 - Electrode testing - to study the current-voltage behavior of the enzymatic electrode and assess its potentiometric and amperometric response in the presence of glycerol.

Specific Objective 2: To evaluate the effectiveness of tethering GIDH-NAD ${ }^{+}$complex onto a gold electrode via FeS mediated wiring system.

The purpose of this study was to optimize and upgrade the molecular wiring system of the glycerol-selective bio-anode for higher electron transfer efficiency using a shorter wiring system based on novel $[\mathrm{Fe}-\mathrm{S}]$ mediation for the attachment of GlDH-NAD ${ }^{+}$to the $\mathrm{Au}$ electrode surface. The specific objective will be tested by performing the following tasks: Task 1 - Enzyme (GIDH) attachment via iron (II) sulfide (FeS) mediation using layer-bylayer (LBL) self-assembly technique.

Task 2 - Characterization of the FeS-based enzyme electrode to confirm SAM formation and electron transfer efficiency using cyclic voltammetry.

Task 3 - Testing the electrochemical phenomena occurring at the upgraded enzyme electrode surface in the presence of the glycerol using potentiometric (OCV 
measurements) and amperometric (cyclic voltammetry, chronoamperometry, and constant potential amperometry) studies.

Specific Objective 3: To compare the current-voltage responses achieved by electrodes constructed using the two wiring systems.

On completion of the tasks of objective 2, a comparison was done between the PQQ-based conventional wiring versus the FeS-based wiring systems. The assessment was be made based on the current-voltage response shown by the two glycerol selective electrodes. 


\section{CHAPTER II}

\section{LITERATURE REVIEW}

The term "bioanode" represents an electrode that utilizes a biological material to catalyze an electrochemical process. The main function of the anode catalyst such as an enzyme, a cell organelle or a whole living cell, is to transport electrons from an electron donor (fuel or substrate) to the supporting electrode surface. Electrocatalysts such as platinum often fail at the task of bioelectrochemical conversions primarily due to the lack of substrate specificity. For example, in anodic oxidation of glycerol cannot be reliably achieved with any metal or chemical catalysts (these often lack product specificity). However, it is easily performed by enzymes or in bacterial cells. While enzyme electrocatalysis suffers drawbacks such as high cost of enzyme production, complex immobilization, lifetime limitation and limited electron transfer; whole cell electrocatalysis also suffer from limitations such as the need for continuous nutrient supply, lack of substrate specificity, lack of product specificity and low electron transfer rates. Evidently, low electron transport is one of the most significant challenges in bioelectrocatalysis.

A detailed literature review was performed to understand the biochemical and electrochemical phenomena that occur at the anode of microbial fuel cells (MFCs) and the factors that affect the performance of MFCs. This review was published as a chapter in the book "Technology and Application of Microbial Fuel Cells" Editor: Chin-Tsan Wang, 
ISBN 978-953-51-1627-1. It is reprinted in the annex section with permission from Intech Open.

Although a microbial cell electrocatalysis system was reviewed, a simple and straightforward enzyme based electrochemical system was preferred for this study. This project addresses the following limitations of the enzyme electrode system: 1) increased electrical resistance as a result of large number or relatively less conductive interfacing molecules used to immobilize the enzyme-coenzyme complex onto the electrode surface; 2) lack of an interfacing agent that is simple in structure (thus offering low resistance) and serves as a single-molecular anchoring agent while also having redox capability to shuttle electrons between the enzyme-coenzyme complex and the electrode surface. 


\section{CHAPTER III}

\section{CONVENTIONAL PQQ-BASED GLYCEROL SELECTIVE BIOANODE - POTENTIOMETRY VS AMPEROMETRY MODE*}

\subsection{Introduction}

Enzymatic bioanodes are electrodes that integrate an enzyme as the active sensing element within an electrochemical transducing system (Ronkainen, Halsall, \& Heineman, 2010). These bioanodes are based on efficient electron-transfer between active site of the immobilized enzyme and the electrode surface (Marcus \& Sutin, 1985). An electrical signal generated at the enzyme-substrate interface must ideally be transduced without any interferences or change for further signal processing (Prodromidis \& Karayannis, 2002). This depends on the wiring system that attaches the enzyme to the electrode. The objective of this study was to fabricate a wiring system to anchor glycerol-dehydrogenase (GIDH) enzyme onto a gold ( $\mathrm{Au}$ ) electrode and to evaluate the efficacy of the wiring system to effectively transport generated charges (as a result of glycerol oxidation) from the enzyme active site to the supporting electrode.

Several glycerol-selective enzymes namely glycerol oxidase, glycerol kinase, glyerol-3phosphate dehydrogenase and glycerol dehydrogenase have been utilized either

\footnotetext{
* Part of the data reported in this chapter is reprinted with permission "Potentiometric vs amperometric sensing of glycerol using glycerol dehydrogenase immobilized via layerby-layer self-assembly." by Mahadevan A, Gunawardena D, Karthikeyan R, Fernando S., 2014, Microchim Acta. 2014:1-9, Copyright [2014] by Springer Vienna.
} 
individually or in combination with other enzymes for glycerol sensing and fuel cell in the past (Goriushkina et al., 2010). As GIDH is insensitive toward oxygen and has higher specific activity, it was decided to be used as the glycerol-sensitive enzyme for this application (Nedović \& Willaert, 2006; Wong \& Whitesides, 1994). GIDH oxidizes glycerol to dihydroxyacetone (DHA) while concurrent reduction of its co-factor, $\mathrm{NAD}^{+}$to NADH according to the following reaction:

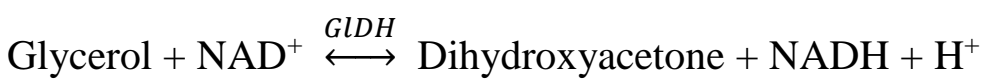
Reaction (1)

Electrochemical oxidation of NADH to $\mathrm{NAD}^{+}$is a highly irreversible process and it occurs with high overpotentials, as values of $0.4,0.7$ and $1 \mathrm{~V}$ vs. standard calomel electrode (SCE) have been reported for carbon, Pt and Au electrodes, respectively (Katz, Shipway, \& Willner, 2010). Therefore, it is important to use a mediator to facilitate continuous transport of electrons from the enzyme active site to the interior of the electrode.

In the past, pyrroloquinoline quinone (PQQ) has been used as a mediator to facilitate cyclic reduction and oxidation of $\mathrm{NAD}^{+}$cofactor. Another advantage of using PQQ is the ability to use its carboxylic acid groups and/or the di-carbonyl site to covalently anchor other moieties. For example, the amine group in cystamine can be covalently linked to a carboxylic-acid-group in PQQ via peptide bond formation whereas the thiol group (in cystamine) can be used to anchor the remainder of the enzyme assembly onto a metal 
(usually gold) electrode. PQQ is directly involved in the oxidation of NADH as follows (Lapenaite et al., 2005):

$\mathrm{PQQ}+\mathrm{NADH} \stackrel{\mathrm{H}+}{\rightarrow}+\mathrm{PQQH}_{2}+\mathrm{NAD}^{+}$

Reaction (2)

$\mathrm{PQQH}_{2} \rightarrow \mathrm{PQQ}+2 \mathrm{H}^{+}+2 \mathrm{e}^{-}$

Reaction (3)

Reaction (1) occurs at the electrode surface when glycerol reaches active site of the enzyme in the presence of $\mathrm{NAD}^{+}$. The $\mathrm{NADH}$ produced then reacts with PQQ to regenerate $\mathrm{NAD}^{+}$, as seen in reaction (2). Reactions (1) and (2) occur for recurring generation of $\mathrm{NADH}$ and $\mathrm{NAD}^{+}$. Appropriately, the amount of redox mediator remains unchanged during the biosensing process (Eftekhari, 2001).

Attachment of PQQ to the NAD ${ }^{+}$co-factor is somewhat intricate. Based on previous (A. Gunawardena, Fernando, \& To, 2008; D. A. Gunawardena, Fernando, Fernando, \& Perera, 2012) work aminophenylboronic acid monohydrate (APB) was selected to be used as a bi-pod anchoring agent to attach PQQ from one side (via peptide bond) and $\mathrm{NAD}^{+}$from the other (via the di-carbonyl (alpha keto acid) - cis-diol chemistry). Analogous electrodes formed by our group (D. A. Gunawardena et al., 2012) as well as other groups had demonstrated good electrocatalytic activity for NADH oxidation (Katz et al., 2010) with other enzyme systems. Thus, the above chemistry was selected to be utilized for the 
present GIDH based electrode. Figure 1. illustrates the wiring scheme of SAMs on the Au electrode surface.

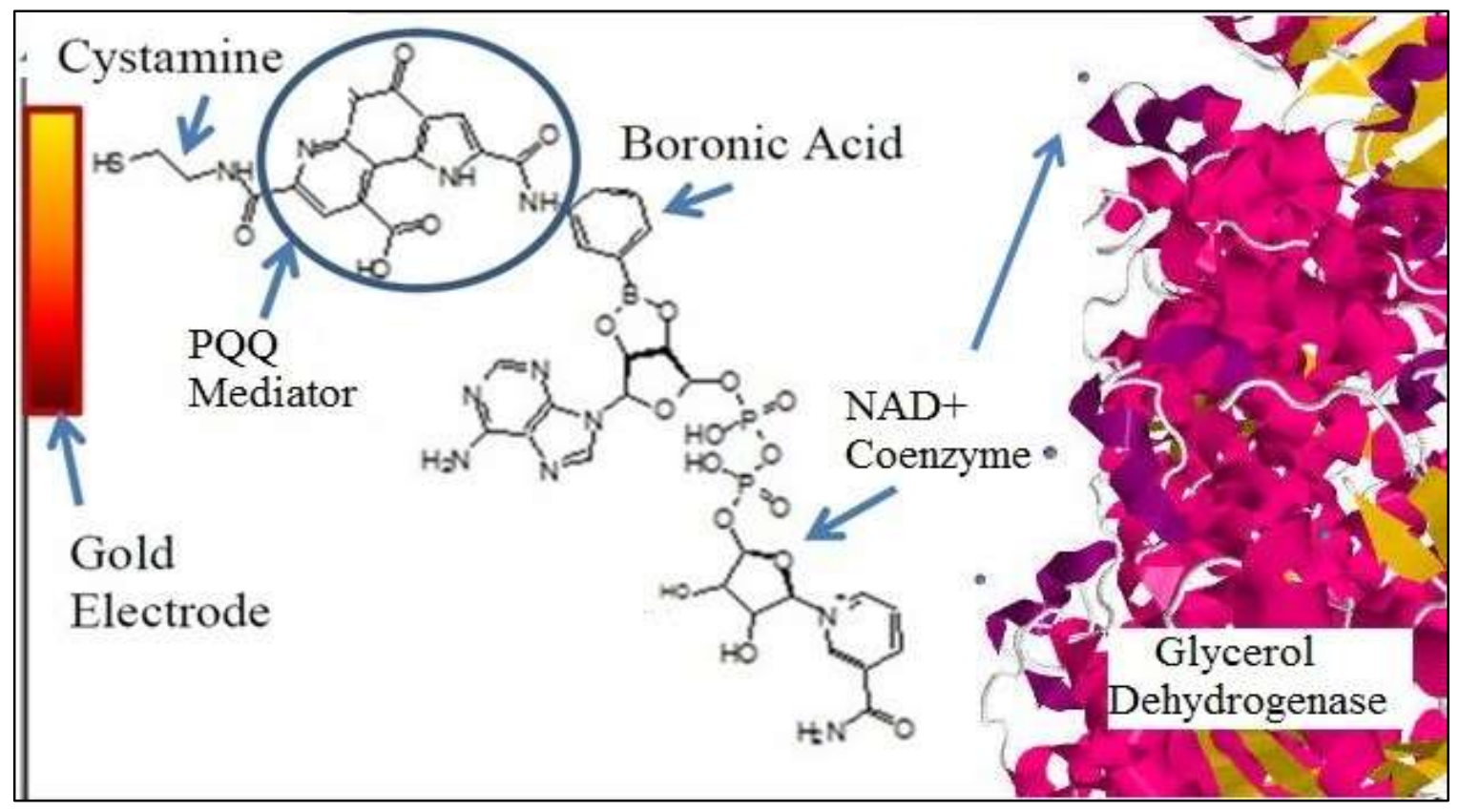

Figure 1. Wiring scheme for the GIDH based enzymatic anode

An enzymatic anode of this sort could be utilized in two modes for analyte detection, i.e., via potentiometry and amperometry. Potentiometry measures the potential difference between the anode and the cathode as a function of analyte concentration whereas amperometry measures the current response of the electrode system as a result of an externally induced potential. Following studies were conducted to understand how the system responds to both these scenarios. Studies were also conducted to verify formation of individual molecular layers. 


\subsection{Materials and Methods}

\subsubsection{Reagents and Apparatus}

$\mathrm{NAD}^{+}$-dependent glycerol dehydrogenase from Cellulomonas sp. (EC.1.1.1.6), ßNicotinamide adenine dinucleotide $\left(\mathrm{NAD}^{+}\right)$, glycerol $\geq 99 \%$, pyrroloquinoline quinone $98 \%$, cystamine dihydro chloride $\geq 98 \%$, 3-aminophenylboronic acid monohydrate - $98 \%$, HEPES buffer and glutaraldehyde were purchased from Sigma-Aldrich, USA (www.sigmaaldrich.com). 1-Ethyl-3-(3-dimethylaminopropyl) carbodiimide (EDC) and $N$-Hydroxysuccinimide (NHS) were purchased from Worthington Biochemical Corp., USA (www.worthington-biochem.com).

A solution of $50 \mathrm{mM} \mathrm{KOH}$ in $35 \%$ wt. $\mathrm{H}_{2} \mathrm{O}_{2}$ was used for cleaning the gold surface. 0.1 M HEPES buffer (pH 7.2) was used to prepare PQQ and 3-aminophenylboronic acid solutions in the presence of $5 \mathrm{mM}$ EDC and $2.5 \mathrm{mM}$ NHS. $3-\mathrm{NAD}^{+}, \mathrm{GlDH}$ and glutaraldehyde solutions were prepared in $0.1 \mathrm{M}$ Phosphate buffer ( $\mathrm{pH} 7$ ). Molecularbiology-grade water, obtained from Sigma-aldrich was used for preparing all aqueous solutions, rinsing and cleaning throughout this study. Au disk working electrodes, $\mathrm{Ag} / \mathrm{AgCl}$ reference electrodes and $\mathrm{Pt}$ auxillary electrodes were purchased from $\mathrm{CH}$ instruments Inc., Austin TX (www.chinstruments.com). The potentiometric and amperometric tests were performed using CHI8003D Potentiostat by $\mathrm{CH}$ Instruments, Inc. 


\subsubsection{Electrode Fabrication}

An important step in electrode fabrication is rigorous cleaning of the electrode surface. For this, initially, the Au electrodes were polished using Alumina powder and rinsed with water. The rinsed electrodes were subjected to ultrasonic cleaning in an ultrasonic bath for 2 min to ensure removal of alumina particles and other impurities from the Au surface. The polished electrodes were then immersed in the gold cleaning solution for $30 \mathrm{~min}$ and rinsed with water. This was followed by a potassium hydroxide potential triple sweep as described by Fischer et al. (Fischer et al., 2009) and a thorough rinse with water before use.

The clean Au electrodes were modified for enzyme attachment via LBL self-assembly of a series of molecules. The procedure described by Zayats et al. (Zayats, Katz, \& Willner, 2002) for lactate electrode was modified according to the requirements of this study. First, the clean $\mathrm{Au}$ electrodes were immersed in a solution of $100 \mathrm{mM}$ cystamine dihydrochloride in water for 1 hour $(\mathrm{H})$. The physisorbed molecules were removed by rinsing the electrode with water. The cystamine attached Au electrodes were dipped in a $3 \mathrm{mM}$ solution of PQQ for $2 \mathrm{H}$ in the presence of EDC and NHS to yield an amide bond between the amino activated Au electrode and carboxyl group on PQQ. The PQQ attached $\mathrm{Au}$ electrodes were then subjected to a $2 \mathrm{H}$ soak in $1 \mathrm{mM} \mathrm{3-aminophenylboronic} \mathrm{acid}$ solution and then rinsed with water. The Au-electrodes were further immersed in $1 \mathrm{mM}$ of $\mathrm{B}_{-\mathrm{NAD}}{ }^{+}$solution for $2 \mathrm{H}$ followed by rinsing with water. The PQQ-NAD ${ }^{+}$ functionalized $\mathrm{Au}$ electrodes were then reacted with $1 \mathrm{mg} \cdot \mathrm{mL}^{-1} \mathrm{GIDH}$ for $2 \mathrm{H}$ and quickly 
rinsed with water and treated with $10 \%(\mathrm{v} / \mathrm{v})$ glutaraldehyde for $20 \mathrm{~min}$ in order to crosslink the enzyme. The enzyme bound Au electrodes were finally cleansed with water to remove any physisorbed materials and dried under nitrogen gas. GIDH-NAD ${ }^{+}$ immobilized $\mathrm{Au}$ electrodes for the biocatalytic oxidation of glycerol were ready for surface and electrochemical characterization.

\subsubsection{Characterization of Fabricated Electrode}

A combined quantitative-qualitative method was used to verify SAM formation. To ensure that each monolayer in the stack of SAMs actually deposited on top of previously functionalized surface, cyclic voltammetry was performed using potassium ferricyanide as the model analyte. The hypothesis here was that formation of each layer will progressively reduce the peak current (at ferrocyanide oxidation or ferricynaide reduction) as a result of increasing internal resistance. Each experimental run consisted of the conventional 3-electrode system (i.e., enzymatic working electrode, Pt counter electrode and $\mathrm{Ag} / \mathrm{AgCl}$ reference electrode) placed in an electrochemical cell unit containing $5 \mathrm{~mL}$ total volume of potassium ferricyanide. Single potential sweep was recorded for each successive layer in the multilayer-SAMs attached to the Au electrode of the same surface area $\left(0.031 \mathrm{~cm}^{2}\right)$. A potential sweep rate of $50 \mathrm{mV} / \mathrm{s}$ was used for all the cyclic voltammetric measurements. Bare Au electrode without any contamination was used as the control electrode. All the experiments were performed at room temperature. Then, Scanning Electron Microscopy in backscatter mode was used to image the electrodes prior to and subsequent to enzyme attachment. Ancillary studies were conducted to ascertain 
the current/voltage response of bare gold (working)- $\mathrm{Pt}$ (counter) and $\mathrm{Ag} / \mathrm{AgCl}$ (reference) electrode system with $1 \mathrm{mM}$ each of $\mathrm{PQQ}, \mathrm{NAD}^{+}$, glycerol and enzyme stimulants (viz. $\left(\mathrm{NH}_{4}\right)_{2} \mathrm{SO}_{4}$ and $\left.\mathrm{MnCl}_{2} \cdot 4 \mathrm{H}_{2} \mathrm{O}\right)$.

\subsubsection{Potentiometric Analysis}

Three-electrode System: The instantaneous open circuit voltages (OCV) of enzyme electrodes were assessed using the conventional 3-electrode system for 0.001-1 M glycerol concentrations. Water containing the enzyme stimulants (hereafter mentioned as WS solution) was used as the carrier electrolyte.

Two-electrode System: Potentiometric assessment of the enzyme electrodes was also conducted with $\mathrm{Ag} / \mathrm{AgCl}$ reference electrode (Chen, Starzmann, \& Liu, 1982). A datalogging multimeter was employed to measure the OCV between the two electrodes for $0.001-1 \mathrm{M}$ glycerol in $5 \mathrm{~mL}$ total volume of the carrier electrolyte. Effect of enzyme stimulants on the potentiometric response of the enzyme electrodes was studied. Water containing the enzyme stimulants i.e. $0.03 \mathrm{M}\left(\mathrm{NH}_{4}\right)_{2} \mathrm{SO}_{4}$ and $0.3 \mu \mathrm{M} \mathrm{MnCl} 2 \cdot 4 \mathrm{H}_{2} \mathrm{O}$ (mentioned as WS solution throughout this study) and pure water (mentioned as W (control for this study)) were used as carrier electrolytes for testing the electrodes. The responses were recorded using the data-logger for $10 \mathrm{~min}$ at the rate of one reading per second to ensure equilibration. 


\subsubsection{Amperometric Analysis}

Amperometric tests were performed to analyze the current response of the enzymatic electrode system for various glycerol concentrations (0.001-1 M). First, cyclic voltammetry was conducted using the typical 3-electrode system placed in a total volume of $5 \mathrm{~mL}$ WS solution. Current responses for potential sweeps between $0 \mathrm{~V}-1.5 \mathrm{~V}$ and $0.665 \mathrm{~V}-1.3 \mathrm{~V}$ were recorded at a $50 \mathrm{mV} / \mathrm{s}$ scan rate.

Furthermore, the electrocatalytic oxidation of glycerol at the enzyme electrode was interrogated using chronoamperometry in order to evaluate the diffusion coefficient(s) of glycerol. The diffusion coefficient reflects the transport phenomena between the electrode and substrate.

\subsection{Results and Discussion}

\subsubsection{Verification of SAM Formation via Electrochemical Analyses}

Figure 2 shows the cyclic voltammograms of bare Au followed by each consecutive layer up to the glutaraldehyde layer. Changes in current and peak splitting of the $\mathrm{Fe}(\mathrm{CN}) 6^{3-/ 4-}$ voltammetry, are attributed to change in electron transfer kinetics (Dowdy \& Leopold, 2010). Stable and definite peaks pertinent to $\mathrm{Fe}^{2+} / \mathrm{Fe}^{3+}$ redox couple are observable for the bare Au electrode. It is observable that the peak currents progressively decrease while peak splitting increases as each successive SAM is attached on the Au surface. Attachment of the final layers, i.e., enzyme and glutaraldehyde, resulted in the lowest peak-currents along with substantial peak shifts. The progressive peak shifting 
indicates increased residual current-voltage drop likely due to increased resistance from each of the attached layers. It has been described before that the well-defined structures of SAMs on the Au surface act as an electron and ion transfer barriers (Lu, Zhang, Zhang, Chen, \& Kang, 2007). The dramatic drop in peak current as the enzyme is interfaced is likely as a consequence of the electrostatic repulsion between the $\mathrm{Fe}(\mathrm{CN}) 6^{3-/ 4-}$ and the carboxyl-terminus of the enzyme (Dowdy \& Leopold, 2010). Another plausible cause is the non-ideal attachment of $\mathrm{NAD}^{+}$coenzyme onto the GIDH apoenzyme. It is also possible that the cross-linking of enzymes (using glutaraldehyde) has caused partial enzyme inactivation due to chemical modification (Migneault, Dartiguenave, Bertrand, \& Waldron, 2004). Nevertheless, this progressive reduction of peak current and increase of resistance after dip-coating the anode with each layer confirms formation of SAMs. 


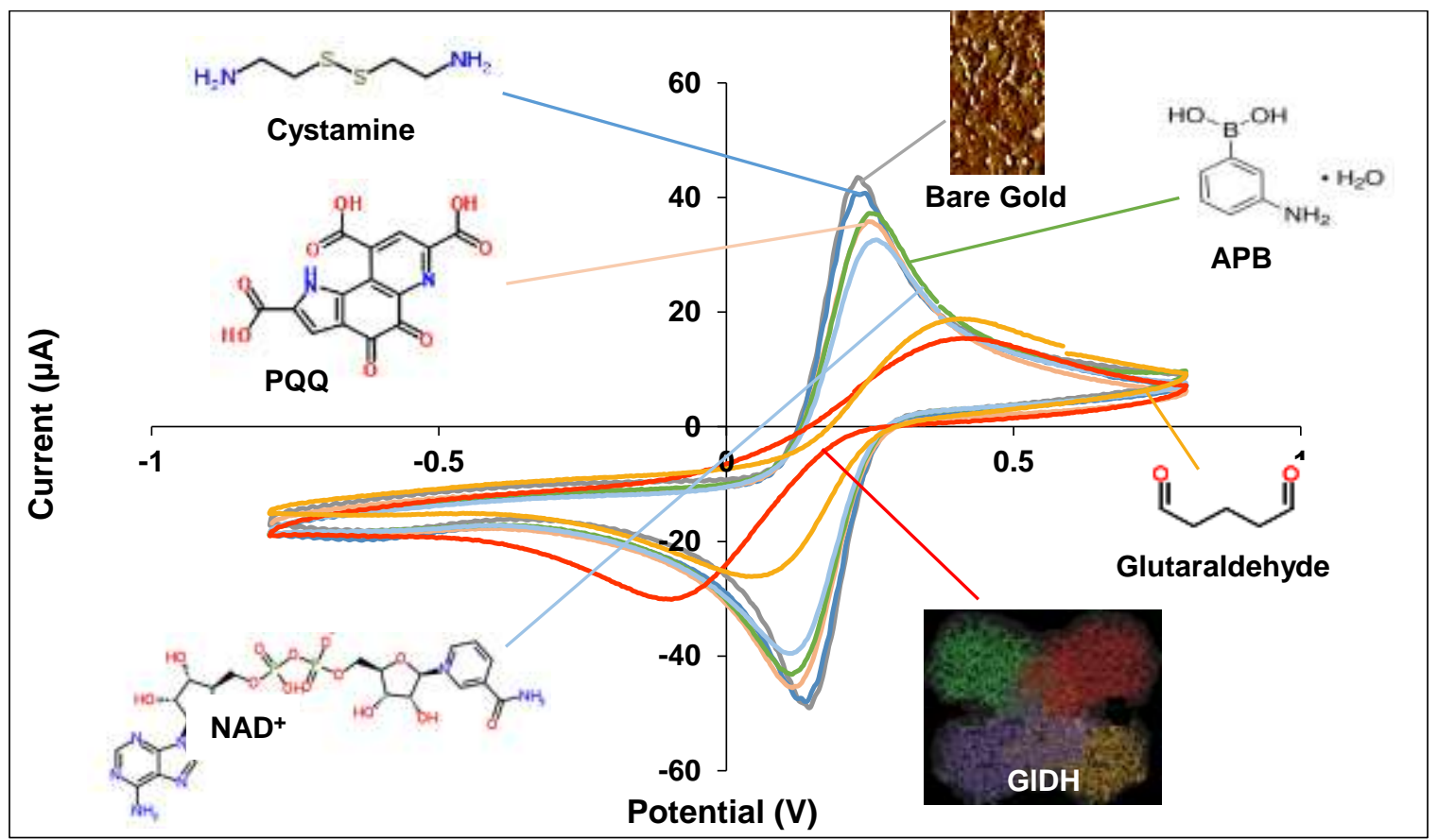

Figure 2. Cyclic voltammograms of bare Au electrode (green) and modified Au electrode after formation of each SAM layer, conducted in $0.01 \mathrm{M}$ potassium ferricyanide with $0.1 \mathrm{M}$ KNO3 as the supporting electrolyte at a potential scan rate of $50 \mathrm{mV} / \mathrm{s}$. Note: Surface area of the Au electrode remained $0.031 \mathrm{~cm}^{2}$ throughout the study.

\subsubsection{Qualitative Surface Characterization}

The enzyme electrodes were then inspected for enzyme attachment on the $\mathrm{Au}$ surface using SEM in the backscatter mode. This mode provides image contrast as a function of elemental composition as well as surface topography. Backscattered electrons are produced by the elastic interactions between the sample and the incident electron beam. The production efficiency for backscattered electrons is proportional to the mean atomic number of sample material, which results in image contrast as a function of composition, i.e., higher atomic number material appears brighter than low atomic number material in a backscattered electron image (Lloyd, 1987). Figures 3 A and B show the SEM images 
of bare and enzyme attached $2 \mathrm{~mm}$ diameter Au disk electrodes and magnified portions of their surfaces.

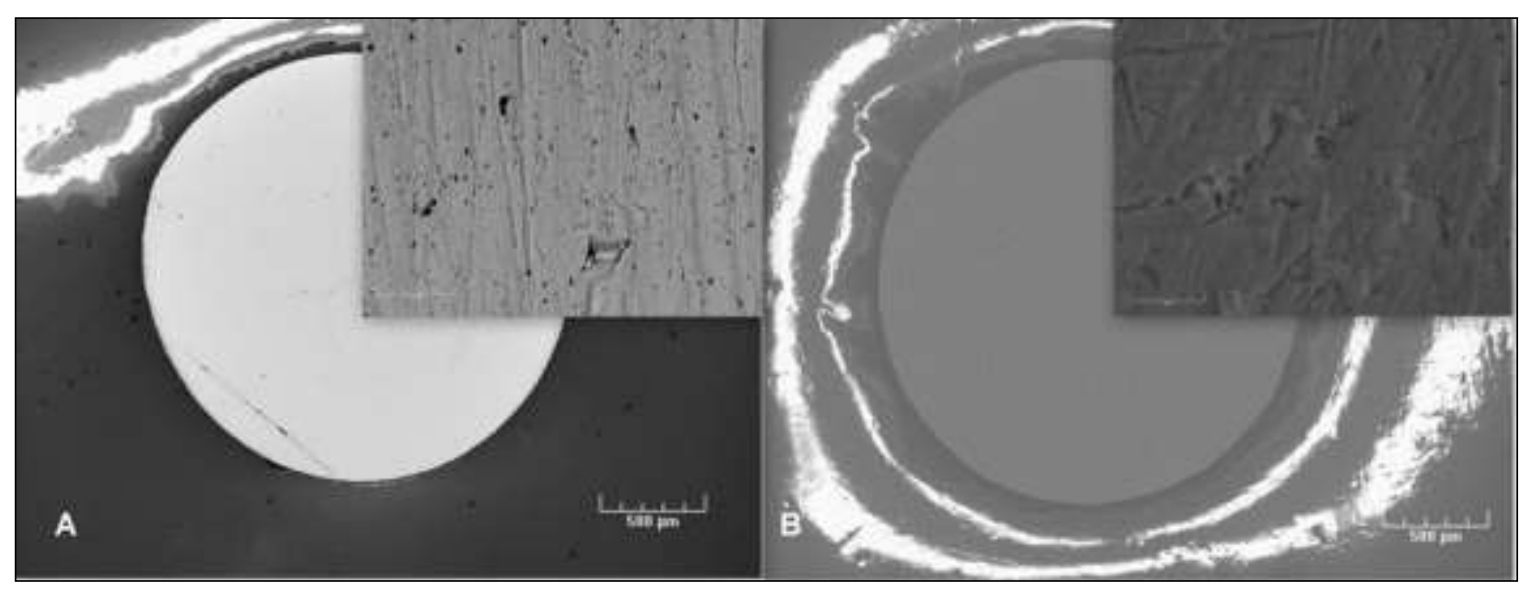

Figure 3. SEM images: (A) Bare Au electrode, (B) Enzyme Attached Au electrode.

A difference in color and texture of the gold surfaces is clearly visible. The magnified image of the bare electrode (A) shows a bright surface with many scratches that could have resulted during manufacture, or by alumina polishing; while that of the enzymeattached electrode (B) shows a dark surface with some patterns but with no evident scratches. The brighter color of the bare electrode surface is due to the high atomic number of $\mathrm{Au}$ and the dark color of the enzyme attached surface can be attributed to the presence of low atomic number structures, a characteristic of the biological materials such as enzymes in this case. 


\subsubsection{Current-Voltage Behavior of the Reagents}

The current/voltage response of bare gold (working)-Pt (counter) and $\mathrm{Ag} / \mathrm{AgCl}$ (reference) electrode system with PQQ, NAD ${ }^{+}$, glycerol and enzyme stimulants (viz. $\left(\mathrm{NH}_{4}\right)_{2} \mathrm{SO}_{4}$ and $\mathrm{MnCl}_{2} \cdot 4 \mathrm{H}_{2} \mathrm{O}$ ) in solution are depicted in Figure 4A \& B. A pure gold working electrode was used since the objective here was to elucidate the redox behavior of aforementioned reagents in solution.
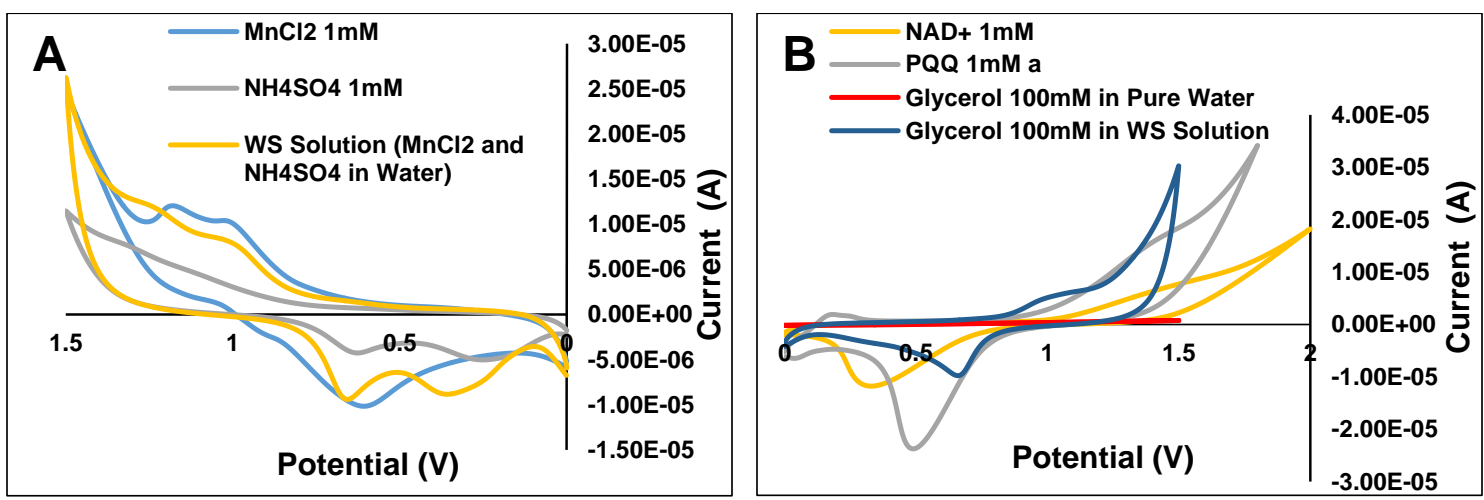

Figure 4. (A \& B) Cyclic voltammograms of individual reagent species used. Scan rate is $50 \mathrm{mV} / \mathrm{s}$.

Table 1. Peak current and half potentials of reagent species obtained from CV

\begin{tabular}{|c|c|c|}
\hline Species & Ip (A) & Eh (V) \\
\hline$\left(\mathrm{NH}_{4}\right)_{2} \mathrm{SO}_{4}$ & $-1.86 \times 10^{-6}$ & 0.714 \\
\hline $\mathrm{MnCl}_{2} \cdot 4 \mathrm{H}_{2} \mathrm{O}$ & $1.68 \times 10^{-6}$ & 1.126 \\
\hline $\mathrm{WS}$ & $-7.219 \times 10^{-6},-2.421 \times 10^{-6}$ & $0.722,0.430$ \\
\hline $\mathrm{NAD}^{+}$ & $-7.53 \times 10^{-6}$ & 0.547 \\
\hline $\mathrm{PQQ}$ & $3.604 \times 10^{-6}$ & 0.129 \\
\hline $\begin{array}{c}\text { Glycerol in Pure } \\
\text { Water }\end{array}$ & - & - \\
\hline Glycerol in WS & $-7.63 \times 10^{-6}$ & 0.724 \\
\hline
\end{tabular}


The reduction potential of $\mathrm{NAD}^{+}(\mathrm{vs} \mathrm{Ag} / \mathrm{AgCl}$ ) was measured to be $0.547 \mathrm{~V}$ whereas for PQQ was $0.129 \mathrm{~V}$ (for comparison, redox potentials reported by others (at different conditions) are: $-0.56 \mathrm{~V}\left(\mathrm{NAD}^{+}\right)$vs SCE (Zhang, Ju, \& Wang, 2011), -0.13 V (PQQ) vs $\mathrm{Ag} / \mathrm{AgCl}$ at neutral pH) (Alkire, Kolb, Lipkowski, \& Ross, 2013).

As can be seen, the peaks for glycerol oxidation is not that evident in the cyclic voltammogram $(\mathrm{CV})$. However, our analyses that will be explained in more detail later (in the amperometric response section) indicated that the peaks that are most evident are those of the enzyme stimulants and the presence of glycerol augments the redox response. It turns out that this current response is proportional to glycerol concentration in solution and could fortuitously be utilized to make fairly accurate (glycerol) concentration predictions. But first, the thermodynamic aspects (i.e., potentiometric response) will be discussed below.

\subsubsection{Potentiometric Analysis}

In this instance, the ability of GIDH to oxidize glycerol and generate a potential was utilized as the sensing modality (rather than interrogating the electrode with an external potential as done in $\mathrm{CV}$ ).

Enzymatic, Pt-counter and Ag/AgCl Three-electrode System: The instantaneous voltage response of the system to varying glycerol concentrations are depicted in Figure

5. The OCV generated by the conventional 3-electrode system stayed more-or-less 
constant despite varying glycerol concentrations. The instantaneous OCV with the pure gold electrode was on average $0.463 \mathrm{~V}$ whereas the enzymatic electrode measured approximately $0.676 \mathrm{~V}$ (on average). Unfortunately, OCV using the 3-electrode system did not prove to be a feasible parameter to detect varying glycerol concentrations.

Enzymatic vs Ag/AgCl Two-electrode System: Equilibrated OCVs between the enzymatic electrode/bare $\mathrm{Au}$ working electrode and $\mathrm{Ag} / \mathrm{AgCl}$ reference electrode (as described by Chen et. al (Chen et al., 1982)) for varying glycerol concentrations in WS (water containing enzyme stimulants) and W (only water) are depicted in Figure 6. It can be observed that, the OCVs produced by bare Au electrodes were not only higher than that of the enzymatic electrode but also showed a decreasing trend or stayed relatively constant to increasing glycerol concentrations in WS and W respectively.

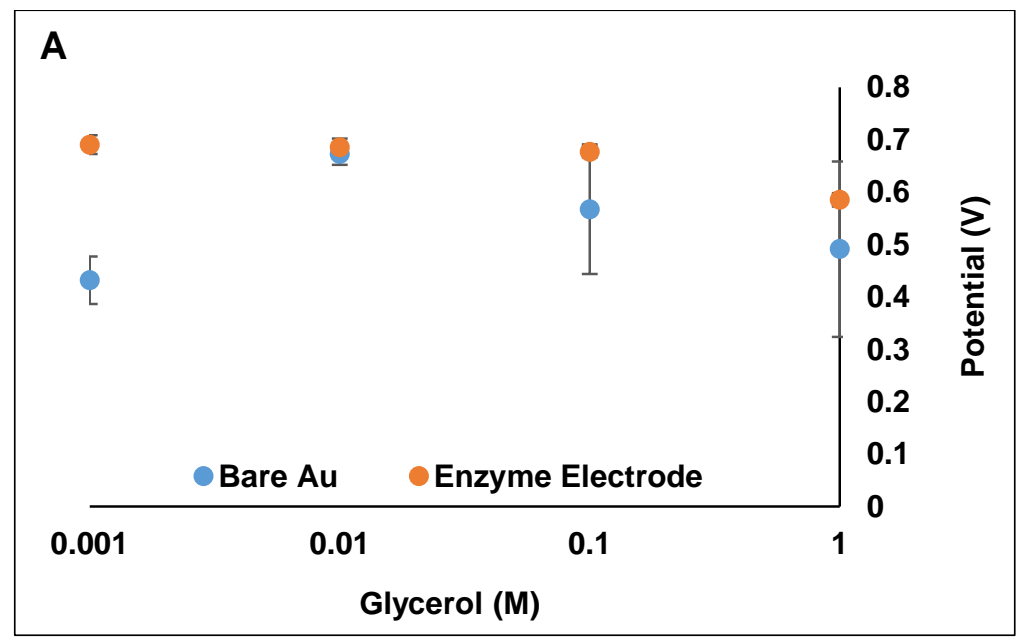

Figure 5. The instantaneous OCV for different glycerol concentrations in WS solution obtained with the conventional 3-electrode system. 


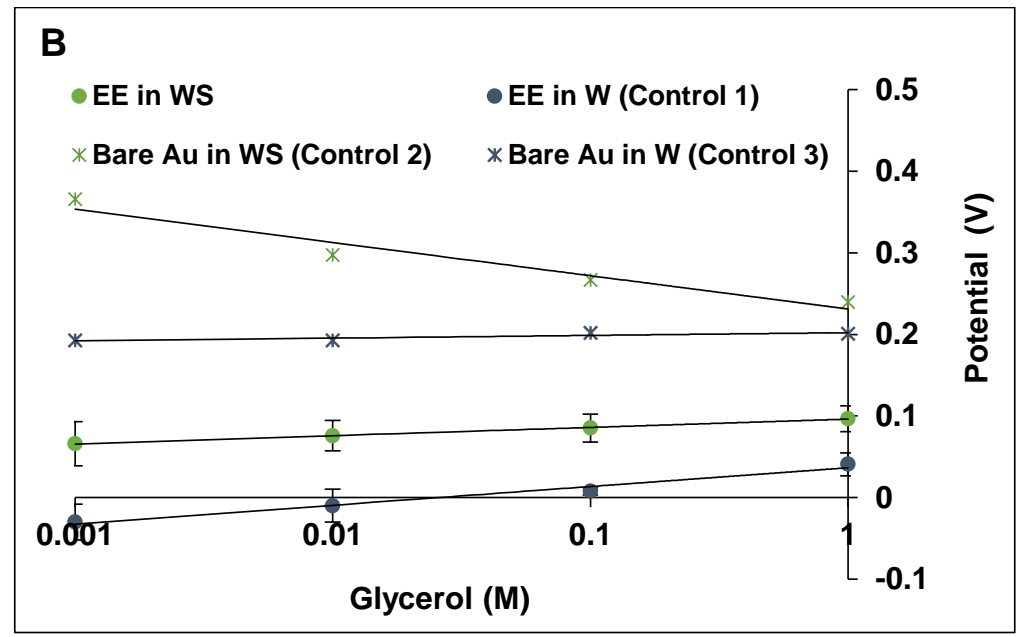

Figure 6. Equilibrated $\mathrm{OCV}$ response (10 $\mathrm{min}$ after reaction initiation) for glycerol concentrations ranging from 0.001-1 $\mathrm{M}$ in the Two-electrode system; W (Water),

WS (Water + Enzyme Stimulants), EE (Enzymatic Electrode). Note: Fitting equations for $\mathrm{EE}$ in WS $\left(\mathrm{y}=0.0044 \ln (\mathrm{x})+0.0962, \mathrm{R}^{2}=0.9979 ; \mathrm{EE}\right.$ in $\mathrm{W}-\mathrm{Control} 1$ $\left(y=0.01 \ln (x)+0.0366, R^{2}=0.9782\right)$; Bare Au in WS - Control $2(y=-0.018 \ln (x)+$ $\left.0.231, R^{2}=0.9448\right)$ and Bare Au in $W-C o n t r o l ~ 3\left(y=0.0015 \ln (x)+0.2021, R^{2}=\right.$ 0.7621).

However, OCVs generated by the enzymatic electrode were well correlated with increasing glycerol concentrations. It can also be observed that, the enzymatic electrode produced higher potentials in WS containing glycerol as opposed to that W containing glycerol. This study confirms with the observation made in a previous section (CurrentVoltage behavior of the Reagents), that the presence of enzyme stimulants (ammonium and manganese) in water augments the redox response of the enzymatic electrode toward glycerol and hence, causes a rise in potentials (when compared with glycerol in pure water). Hence, WS solution was used as the carrier electrolyte in all subsequent experiments. The outcome of these observations is that this two-electrode system where the reference electrode also acts as the working electrode (cathode) could also be used as 
a direct glycerol sensor. However, the drawback of potentiometry is the need to wait till the system equilibrates and thus amperometry was attempted as a means to get faster and more accurate responses.

\subsubsection{Amperometric Response of the Enzymatic Electrode}

The cyclic voltammograms between 0 and $1.5 \mathrm{~V}$ potential range were obtained to study the current voltage behavior of the enzymatic-electrode/glycerol system. The electrode controls used were bare gold whereas the reagent control was WS solution without glycerol.

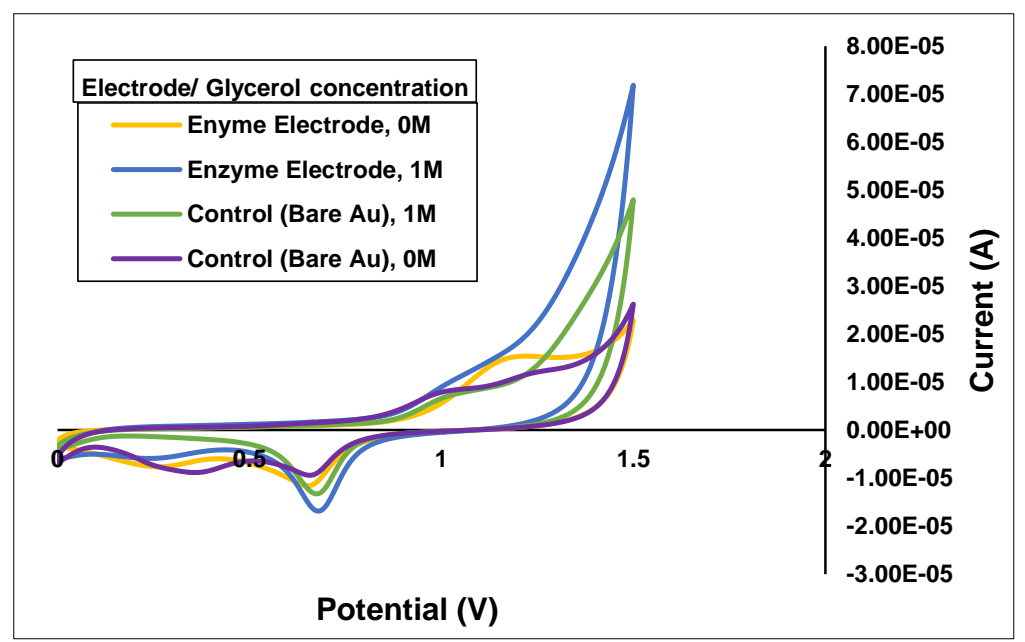

Figure 7. Cyclic voltammograms for enzyme electrode and control (Bare Au) with and without glycerol diluted with water containing enzyme stimulants (WS). Scan rate is $50 \mathrm{mV} / \mathrm{s}$.

The bare gold control in enzyme stimulants produced two distinct anodic current peaks (and corresponding cathodic current peaks) pertinent to stimulants $\left(\mathrm{NH}_{4}\right)_{2} \mathrm{SO}_{4}$ and 
$\mathrm{MnCl}_{2} \cdot 4 \mathrm{H}_{2} \mathrm{O}$ with the distinct anodic and cathodic peaks around $1.2-1.3 \mathrm{~V}$ and $0.665 \mathrm{~V}$ respectively (as can be seen in Figure 7). This dominant peak current essentially increases with enzyme attachment. It is interesting that the peak current was highest at highest glycerol concentration (i.e., $1 \mathrm{M}$ ). Analogous peak current variation was observed for cathodic currents. Based on these observations, it was determined to elucidate the peak current response for different glycerol concentrations selecting the sweep range between the two observed anodic and cathodic peaks (i.e., $0.665 \mathrm{~V}$ and $1.3 \mathrm{~V}$ ). The results of the $\mathrm{CV}$ s for sweep range between $0.665 \mathrm{~V}$ and $1.3 \mathrm{~V}$ at glycerol concentrations of $0-1 \mathrm{M}$ are depicted in Figure 8.

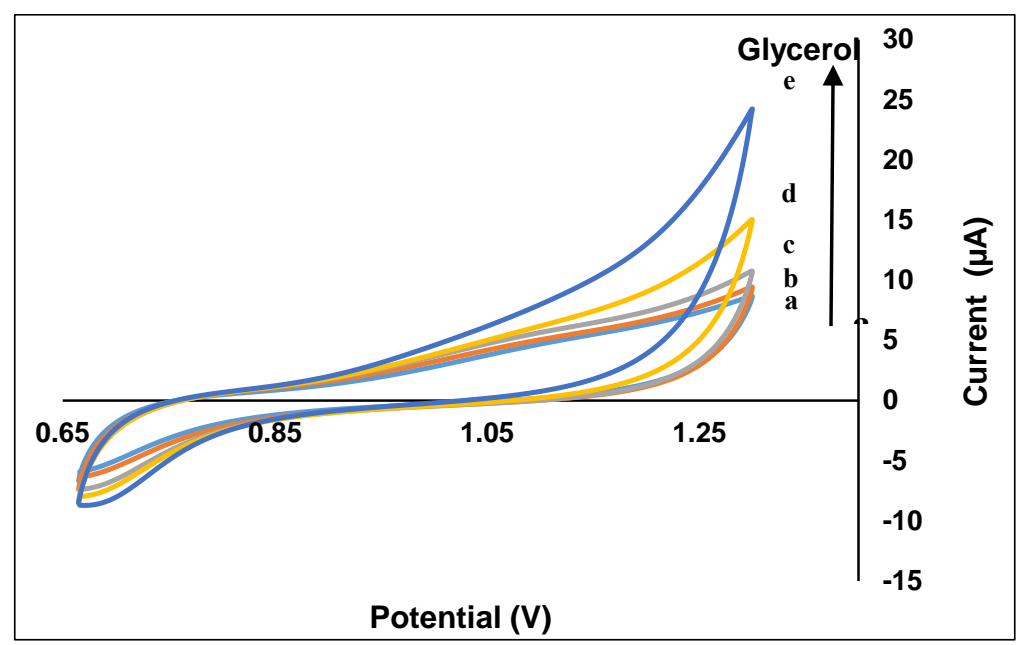

Figure 8. Cyclic voltammograms for enzyme electrode in increasing concentrations of glycerol (a-0 M, b-0.001 M, c- $0.01 \mathrm{M}, \mathrm{d}-0.1 \mathrm{M}$ and e - $1 \mathrm{M})$ diluted with WS solution. Scan rate is $50 \mathrm{mV} / \mathrm{s}$. 


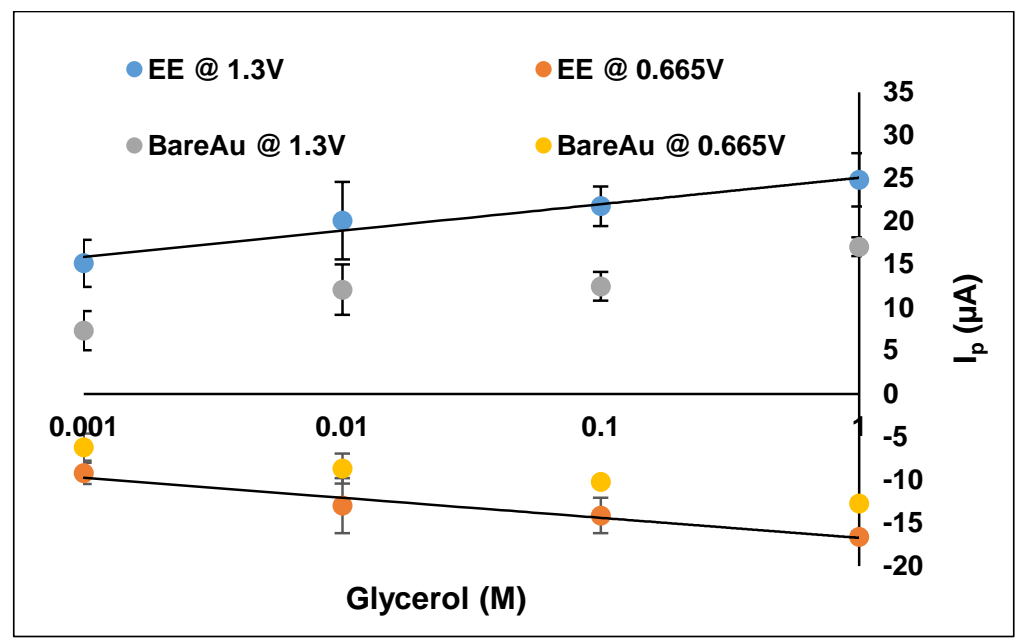

Figure 9. Peak current (Ip) at $1.3 \mathrm{~V}$ and $0.665 \mathrm{~V}$ vs. glycerol concentrations measured by enzymatic electrode (EE) using CV scans between 0 to $1.5 \mathrm{~V}$. Note: Fitting equations for EE @ $1.3 \mathrm{~V}$ is $1.3337 \ln (x)+25.092, R^{2}=0.9595$ and $E E @$ $0.665 \mathrm{~V}$ is $-1.01 \ln (x)-16.734, R^{2}=0.9578$.

It could be seen in Figure 8 that anodic current peaks has a remarkable correlation with glycerol concentration. Cathodic currents pertinent to glycerol reduction (i.e., captured via $\mathrm{NH}_{4}$ reduction at $0.665 \mathrm{~V}$ ) also correlated well with the analyte concentration. To further enumerate the relationship between glycerol concentration and peak currents, correlation plots were developed between glycerol concentration and anodic and cathodic currents (Figure 9). It could be noted from Figure 7B that both anodic and cathodic peak currents $\left(\left|I_{a}\right|\right.$ and $\left.\left|I_{c}\right|\right)$ have a strong logarithmic correlation with glycerol concentration (between 0.001 and $1 \mathrm{M})$.

Following these encouraging results, it was necessary to estimate the (glycerol concentration) range at which this bioanode will stay accurate. The range will be governed (to a large extent) by the diffusion coefficient of the system. In order to ensure that the 
system was within the diffusion-controlled region, the diffusion coefficient was measured. This could be verified by looking at the slope of the Cottrell plot.

To calculate the diffusion coefficient of the system, chronoamperograms were generated for different glycerol concentrations (Figure 10; Initial E $=0.665 \mathrm{~V}$ and Final E $=1.3 \mathrm{~V}$ ). The oxidative and reductive chronoamperograms appear to be symmetrical. Accordingly, the oxidation amperogram was used to deduce $\mathrm{I}$ vs $\mathrm{t}^{-1 / 2}$ (where $\mathrm{t}$ is the time in $\mathrm{s}$ ) (Figure 11). Cottrell's law (Bard \& Faulkner, 1980) describes the current corresponding to the diffusion-controlled electrochemical reaction for an electroactive material with diffusion coefficient given by the equation:

$$
I=\frac{n F A \sqrt{D} C}{\sqrt{\pi t}}
$$

where, $\mathrm{D}$ is the diffusion coefficient $\left(\mathrm{cm}^{2} \mathrm{~s}^{-1}\right), \mathrm{C}$ is the bulk concentration $\left(\mathrm{mol} . \mathrm{cm}^{-3}\right)$, and n, F and A are electron number, Faraday number, and electrode surface area, respectively. Accordingly, the slope of a plot between I vs $\mathrm{t}^{1 / 2}$ for the given glycerol concentrations results in an expression of which the average diffusion coefficient was derived to be 1.68 $\mathrm{x} 10^{-5} \mathrm{~cm}^{2} \mathrm{~s}^{-1}$. The calculated D values for different concentrations are depicted in Figure 12. Based on this analysis, it appears that the Diffusion Coefficient values decrease with increasing glycerol concentrations. 


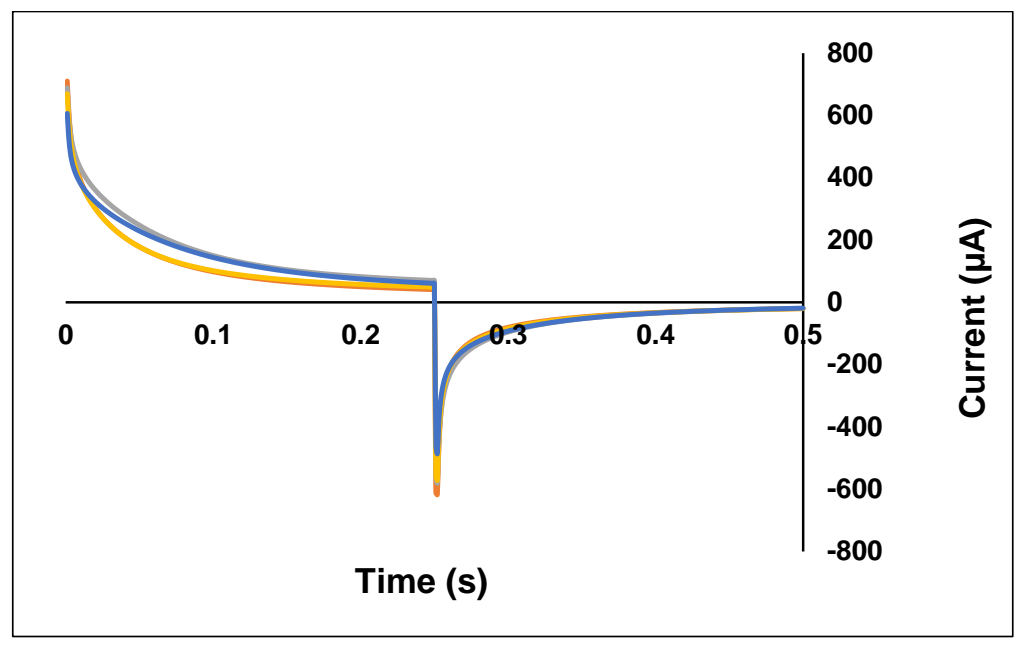

Figure 10. Chronoamperograms for PQQ-based enzyme electrode in $0.001-1 \mathrm{M}$ glycerol

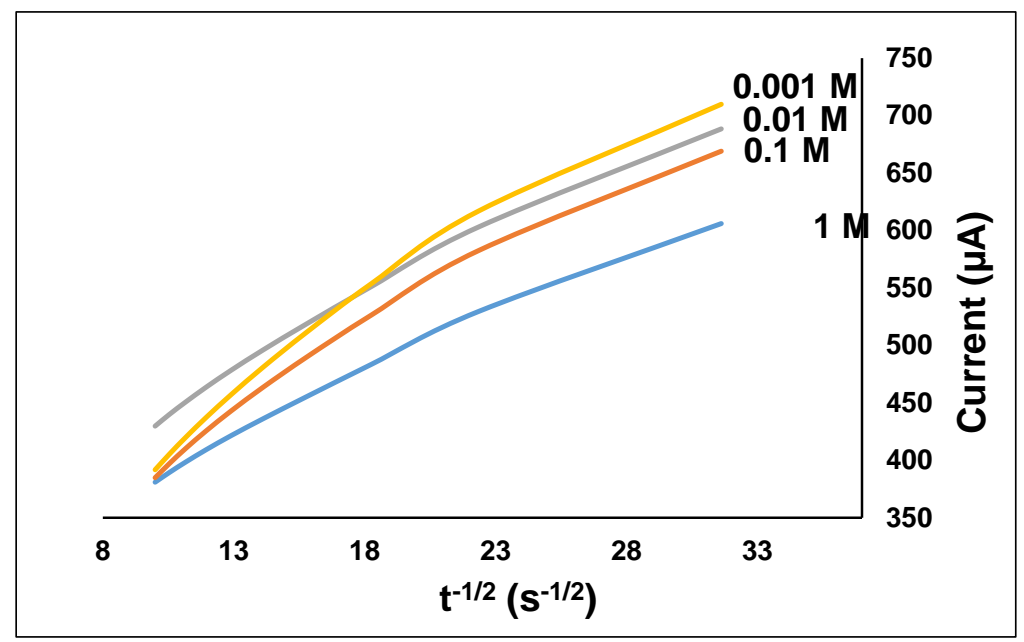

Figure 11. Cottrell plot (I vs t-1/2) obtained from chronoamperograms of PQQbased enzyme electrode in $0.001-1 \mathrm{M}$ glycerol 


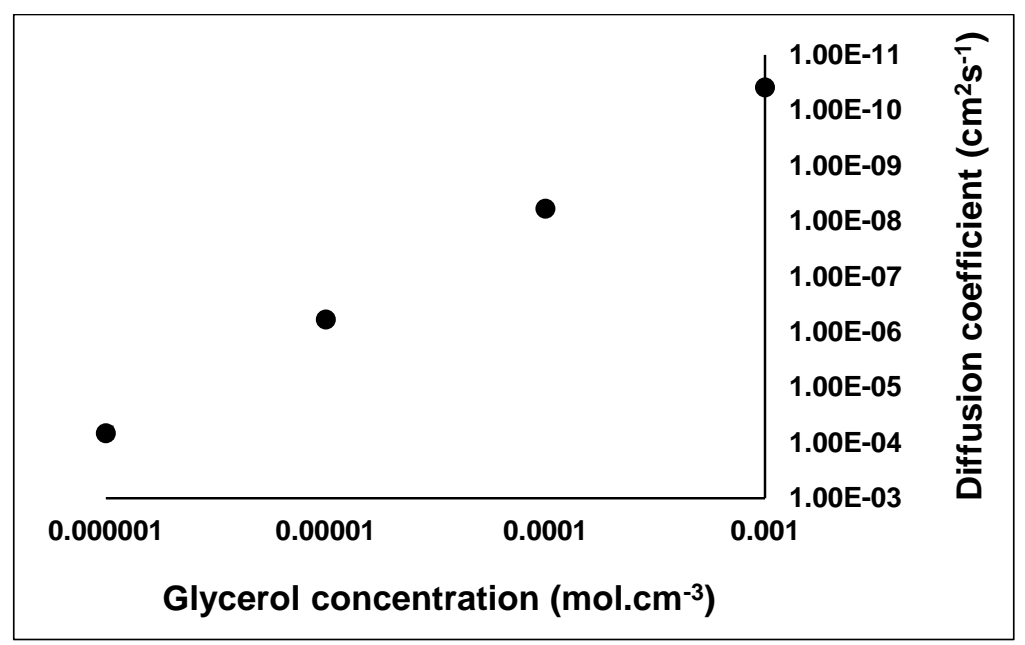

Figure 12. Correlation of bulk concentration and diffusion coefficient. Initial $\mathbf{E}=$ $0.665 \mathrm{~V}$ and Final $\mathrm{E}=1.3 \mathrm{~V}$ for this study.

\subsection{Conclusions}

A glycerol-selective bioanode was developed to quantify glycerol concentrations in aqueous media based on the association of Au electrode and the apoenzyme GIDH via a wiring system sequence consisting of cystamine, PQQ, 3-aminophenylboronic acid, $\mathrm{NAD}^{+}$and glutaraldehyde. The combined cyclic voltammetry - SEM method confirmed the layer-by-layer self-assembly of molecules required to attach the enzyme onto the electrode. A potentiometric analysis of the enzymatic electrode using the conventional 3electrode system revealed that instantaneous OCV was not a good modality to measure varying (i.e., 0 - $1 \mathrm{M}$ ) glycerol concentrations. However, equilibrated OCV between a two-electrode system that used $\mathrm{Ag} / \mathrm{AgCl}$ as the composite working/reference electrode had a positive correlation with increasing glycerol concentrations. This study also confirmed the importance of using the enzyme stimulants for enhanced redox response which could be attributed to their role in increasing reaction specificity of GIDH for 
glycerol. This was further confirmed by an amperometric study which revealed that peak currents pertinent to oxidation or reduction of the enzyme stimulants could be used to measure glycerol concentration. Based on a chronoamperometry study, the diffusion coefficients of glycerol were evaluated to be $1.68 \times 10^{-5} \mathrm{~cm}^{2} \mathrm{~s}^{-1}$. The obtained glycerolselective bioanode which can be used in dual-mode gave a proportional amperometric and potentiometric response with a large working range of 0.001-1M glycerol. 


\section{CHAPTER IV}

\section{A NOVEL IRON-SULFIDE BASED MOLECULAR-WIRE FOR ENHANCING CHARGE TRANSPORT OF GLYCEROL SELECTIVE BIOANODE - A COMPARISON WITH THE PQQ- BASED CONVENTIONAL BIOANODE}

\subsection{Introduction}

Immobilization of redox enzymes or oxidoreductases has been widely reported for the construction of enzyme electrodes (specifically, bioanodes) for various applications such as biosensors, fuel cells and other bioelectronics (Falk, Blum, \& Shleev, 2012; Schmidt \& Schuhmann, 1996; Z. Zhu, Sun, Zhang, \& Zhang, 2012). The overall effectiveness of these enzyme-based electrochemical devices are heavily dependent on the ability of the interfacing molecules (wiring system that attaches enzymes to the electrode) to successfully harvest and transport charges from the outer oxidizing point (enzyme activesite) to the inner electrode surface. (Heller, 1992).

Current technology uses a series of molecules known as "molecular wires" to attach the apoenzyme-coenzyme complex onto the supporting electrode surface (Gooding et al., 2003; B. Willner, Katz, \& Willner, 2006; Zebda et al., 2011). For example, a glycerol oxidizing bio-anode described previously in Chapter II (as a control for this study) used cystamine, mediator Pyrroloquinoline quinone (PQQ) and cross-linking agent 3- 
aminophenylylboronic acid along with the aid of 1-Ethyl-3-(3-dimethylaminopropyl) carbodiimide and N-Hydroxysuccinimide to tether glycerol dehydrogenase- Nicotinamide adenine dinucleotide $\left(\mathrm{NAD}^{+}\right)$apoenzyme-coenzyme complex onto a gold electrode surface (see Figure 13). Although this molecular wiring system was successful in immobilizing the enzyme to the electrode, the inherently low conductivity of these organic tethering molecules ( $\mathrm{Li}$ et al., 2006; Ramachandran et al., 2003) made the electron transport process highly constrained; therefore, resulting in low current density and low sensitivity (when used as glycerol biosensor). Thus, lack of effective molecular wiring systems that can allow unimpeded charge transport is a significant problem and hinders fully harnessing the tremendous potential of bioelectronics devices. Hence, replacing the present intricate wiring system with a simple molecule with correct electrical properties and required prosthetic groups to anchor the enzyme system onto an electrode surface may be the most pragmatic approach to overcome this challenge. 


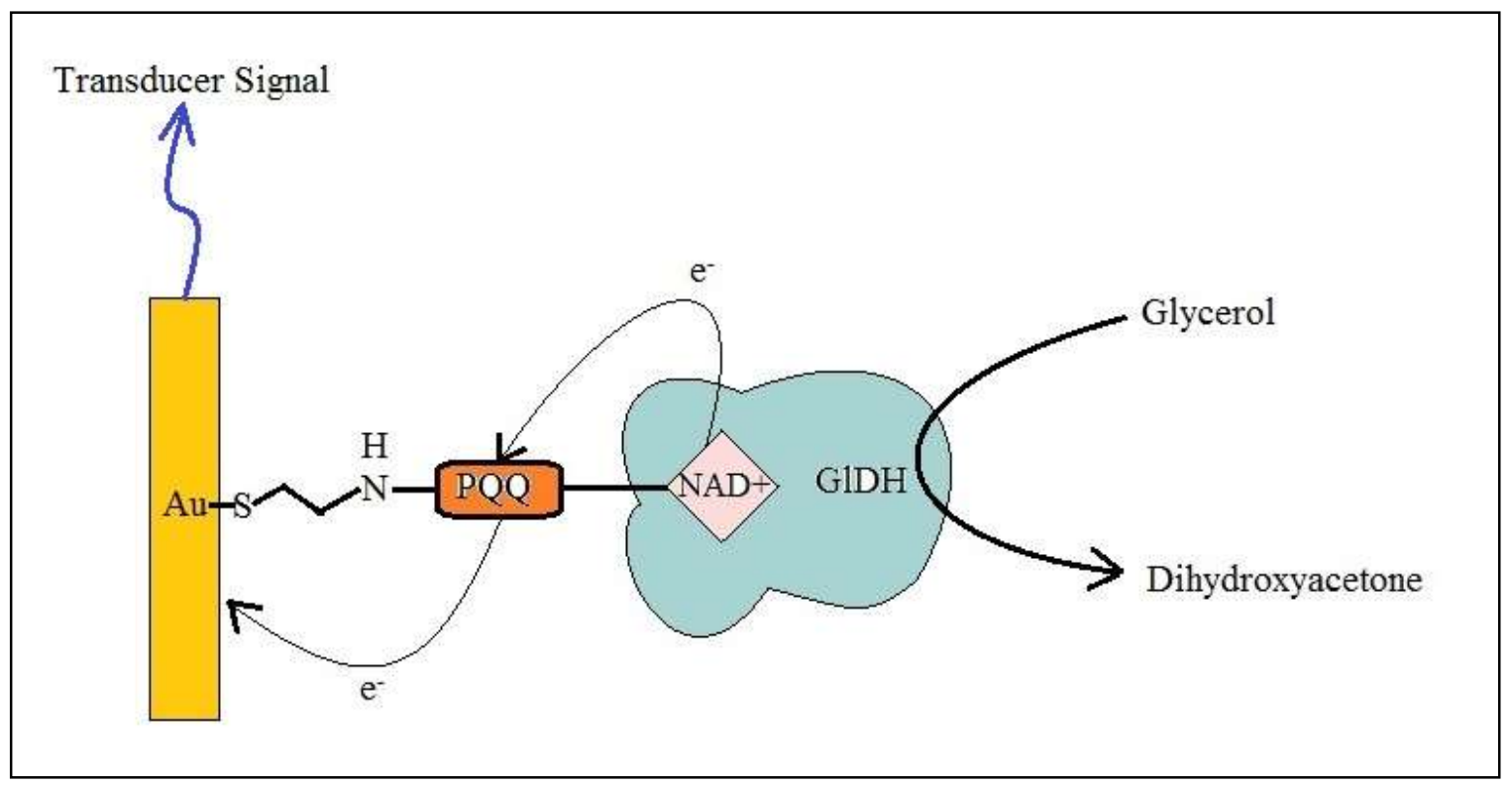

Figure 13. Response mechanism of conventional PQQ-based enzyme electrode

Although the wiring system could be shortened by directly attaching the coenzyme onto the metal surface, this is not possible due to a limitation associated with the coenzyme, $\mathrm{NAD}^{+} . \mathrm{NAD}^{+}$reduces irreversibly with high over potentials interrupting the electron flow generated at the enzyme active site (Katz et al., 2010). To circumvent this, mediators are used to abstract the electron from $\mathrm{NAD}^{+}$(via reduction) and immediately oxidize shuttling it to an adjacent moiety (Radoi \& Compagnone, 2009; Tse \& Kuwana, 1978).

Ironically, mediators such as osmium complexes, PQQ or ferrocene (Leech, Kavanagh, \& Schuhmann, 2012) that have been attempted to date by the research community do not possess the sulfur groups that allow direct attachment of the mediators onto metal surfaces. Consequently, other sulfur-containing molecules are used to covalently attach the mediating molecule onto a metal surface (while in other approaches, the redox enzymes 
are incorporated with nanoparticles and indirectly attached with the electrode surface via suitable cross-linkers/orienting molecules) (Xiao, Patolsky, Katz, Hainfeld, \& Willner, 2003). Ferrocene derivatives such as ferrocenylalkanethiols that have thiol compounds attached to ferrocene have been used successfully for tethering redox enzymes to gold electrode (Ishige, Shimoda, \& Kamahori, 2009). However, the long chain alkyl groups in these compounds escalate the electron transfer resistance due to greater packing densities of SAMs formed on the electrode surface than the short-chain thiols (Crittenden, Sund, \& Sumner, 2006; Ding, Chang, Wu, Lai, \& Chang, 2005).

So, until now, there has been an evident gap in knowledge of a molecule that collectively has: redox capabilities to shuttle electrons, sulfur groups to allow attachment onto metal surfaces, binding affinity to the enzyme end and short enough to have enhanced electron transport properties.

A novel Fe-S-based enzyme electrode is described in this chapter where iron co-ordinates with the heterocyclic nitrogen atoms in imidazole-diazine moieties of $\mathrm{NAD}^{+}$anchoring the apoenzyme-coenzyme complex while sulfur allowing direct attachment of the composite structure onto a gold electrode surface. The inspiration roots to iron-sulfur complexes being the first-link between protein and the mediating molecules in the mitochondrial electron transport chain to abstract electrons from $\mathrm{NAD}^{+}$(Beinert, Holm, \& Münck, 1997; Brzóska, Meczynska, \& Kruszewski, 2006; Johnson, Dean, Smith, \& Johnson, 2005). An attempt to mimic this step in vitro has been described in this chapter. 
As a working model, a glycerol-sensitive electrode, based on direct attachment of glycerol-dehydrogenase (GlDH)-NAD ${ }^{+}$apoenzyme-coenzyme complex to a supporting gold electrode using Iron (II) sulfide mediation is described. The electrochemical response of the novel simplified electrode is compared with the conventionally wired electrode in the presence of glycerol. The parameters studied include amperometric and potentiometric response of the enzyme electrodes in the presence of the analyte, glycerol.

\subsection{Materials and Methods}

\subsubsection{Reagents and Apparatus}

Iron (II) sulfide (FeS), $\mathrm{NAD}^{+}$-dependent glycerol dehydrogenase from Cellulomonas sp. (EC.1.1.1.6), B-Nicotinamide adenine dinucleotide $\left(\mathrm{NAD}^{+}\right)$, glycerol $\geq 99 \%$ and glutaraldehyde were purchased from Sigma-Aldrich, USA (www.sigmaaldrich.com). A solution of $50 \mathrm{mM} \mathrm{KOH}$ in $35 \%$ wt. $\mathrm{H}_{2} \mathrm{O}_{2}$ was used for cleaning the gold surface. While FeS was suspended in $\geq 99.5 \%$ ethanol; $\beta-\mathrm{NAD}^{+}, \mathrm{GlDH}$ and glutaraldehyde solutions were prepared in 0.1 M Phosphate buffer ( $\mathrm{pH} 7$ ). Molecular-biology-grade water, obtained from Sigma-aldrich was used for preparing all aqueous solutions, rinsing and cleaning throughout this study. $2 \mathrm{~mm}$ Au disk working electrodes, $\mathrm{Ag} / \mathrm{AgCl}$ reference electrodes and $\mathrm{Pt}$ auxillary electrodes were purchased from $\mathrm{CH}$ instruments Inc., Austin TX (www.chinstruments.com). The potentiometric and amperometric tests were performed using CHI8003D Potentiostat by $\mathrm{CH}$ Instruments, Inc. Water containing the enzyme stimulants viz. $\left(\mathrm{NH}_{4}\right)_{2} \mathrm{SO}_{4}$ and $\mathrm{MnCl}_{2} \cdot 4 \mathrm{H}_{2} \mathrm{O}$ was used as the carrier electrolyte throughout the study. 


\subsubsection{Electrode Fabrication}

Layer-by-layer self-assembly by dip-coating method was used to fabricate the FeSmodified enzyme electrodes. First, the Au electrodes were prepared for modification by following the three-step rigorous cleaning procedure as described previously in Chapter II, sub-section Electrode Fabrication under Materials and Methods. The clean Au electrodes were first immersed in $0.3 \mathrm{M} \mathrm{FeS}$ suspended in ethanol for $2 \mathrm{H}$. The FeSmodified electrodes were further subjected to immersion in $1 \mathrm{mM}$ of $B-\mathrm{NAD}^{+}$for $2 \mathrm{H}$ and then $1 \mathrm{mg} \cdot \mathrm{mL}^{-1} \mathrm{GIDH}$ for $2 \mathrm{H}$. Finally, the FeS-NAD ${ }^{+}-\mathrm{GIDH}$ functionalized electrodes were treated with $10 \%(\mathrm{v} / \mathrm{v})$ glutaraldehyde for $20 \mathrm{~min}$ in order to crosslink the enzyme. Every step in the dip-coating process was followed by rinsing the electrodes with water to eliminate physisorbed molecules.

\subsubsection{Characterization of Fabricated Electrode}

SAM formation of each interfacing molecule viz. FeS, NAD+, GIDH, glutaraldehyde was verified using cyclic voltammetry in ferricyanide. The parameter and procedure previously described in Chapter II was followed.

\subsubsection{Potentiometric and Amperometric Analyses}

The potentiometric and amperometric analyses of the glycerol-selective bioanode were conducted as described in Chapter II, section Materials and Methods. As it is considered unnecessary, equilibrated potentiometric assessment using the two-electrode system is not reported for new enzyme electrode. Water containing the enzyme stimulants was used as 
the carrier electrolyte for all potentiometric and amperometric tests conducted to assess glycerol response of the enzyme electrodes.

\subsection{Results and Discussion}

The FeS-based enzyme electrode was constructed using a simple layer-by-layer selfassembly method. The procedure involved dip-coating a clean gold ( $\mathrm{Au}$ ) electrode in solutions containing each tethering molecule sequentially as shown in Figure 14.

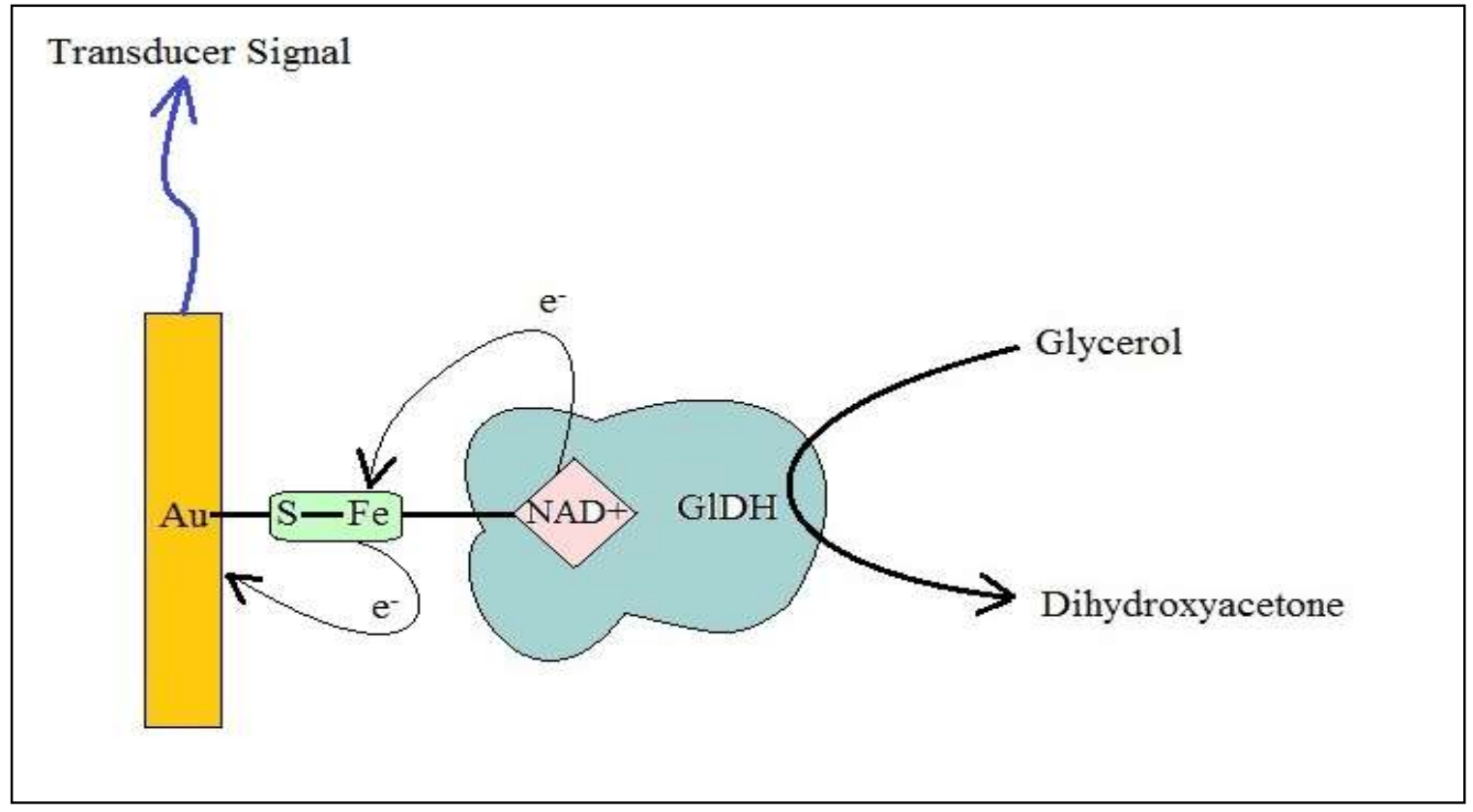

Figure 14. Wiring scheme and response mechanism of the Fe-S-based enzyme electrode

In short, a clean Au electrode was first dipped in FeS solution in pure ethanol (FeS cannot be dissolved in water due to its instability in an aqueous environment). The Fe-S 
functionalized electrode was then treated with $\mathrm{NAD}^{+}$(in aqueous media) to promote its attachment via Fe co-ordination with the heterocyclic nitrogen atoms in imidazole-diazine moieties of $\mathrm{NAD}^{+}$. The electrode was then dipped in a solution containing the apoenzyme for GIDH to interface with its coenzyme $\mathrm{NAD}^{+}$and glutaraldehyde was used to crosslink the enzyme layer (Note: $\mathrm{NAD}^{+}, \mathrm{GlDH}$ and glutaraldehyde were in aqueous buffer solutions).

Cyclic voltammograms (CVs) with ferricyanide shown in Figure 15. was used to verify SAMs formation on the modified Au electrode (constant surface area, $0.031 \mathrm{~cm}^{2}$ ). A bare Au electrode without any contamination was used as the control. 


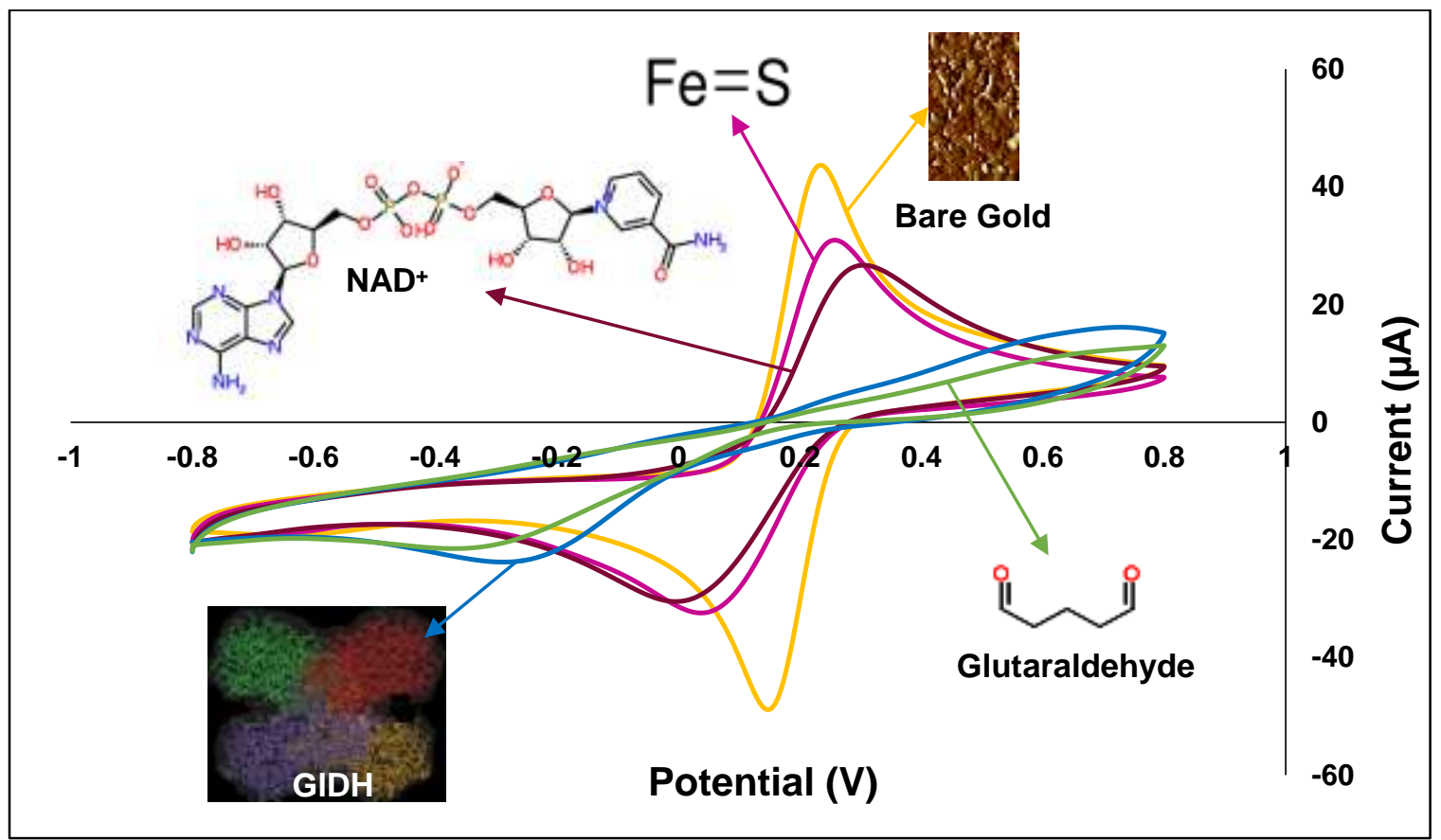

Figure 15. Cyclic voltammograms of bare Au electrode (yellow) and modified Au electrode after formation of each SAM layer, conducted in $0.01 \mathrm{M}$ potassium ferricyanide with $0.1 \mathrm{M}$ KNO3 as the supporting electrolyte at a potential scan rate of $50 \mathrm{mV} / \mathrm{s}$. Note: Constant surface area of the Au electrode, $0.031 \mathrm{~cm}^{2}$ was used throughout the study.

Changes in current and peak splitting of the $\mathrm{Fe}(\mathrm{CN}) 6^{3-/ 4-}$ voltammetry, are attributed to change in electron transfer kinetics caused by the blocking behavior of the densely packed modifiers on the Au electrode surface (Dowdy \& Leopold, 2010). Decrease in current of $\mathrm{Fe}(\mathrm{CN})_{6}{ }^{3-}$ and increasing peak shift can be observed as each successive SAM is attached on the $\mathrm{Au}$ surface. Final layers of enzyme GIDH and glutaraldehyde have the lowest current along with a substantial peak shift. Peak shift indicates the loss of reversibility of the redox couple as the electrode interface is effectively blocked due to formation of densely packed structures on Au surface. 
Potentiometric Analysis of the enzyme electrode was carried out to study the voltage behavior in response to glycerol. Instantaneous open circuit voltages (OCV) of enzyme electrodes were measured using the conventional 3-electrode system (i.e., enzymatic working electrode, $\mathrm{Pt}$ counter electrode and $\mathrm{Ag} / \mathrm{AgCl}$ reference electrode) for 0.001-1 M glycerol concentrations. Water containing the enzyme stimulants viz. $\left(\mathrm{NH}_{4}\right)_{2} \mathrm{SO}_{4}$ and $\mathrm{MnCl}_{2} \cdot 4 \mathrm{H}_{2} \mathrm{O}$ was used as the carrier electrolyte throughout the study.

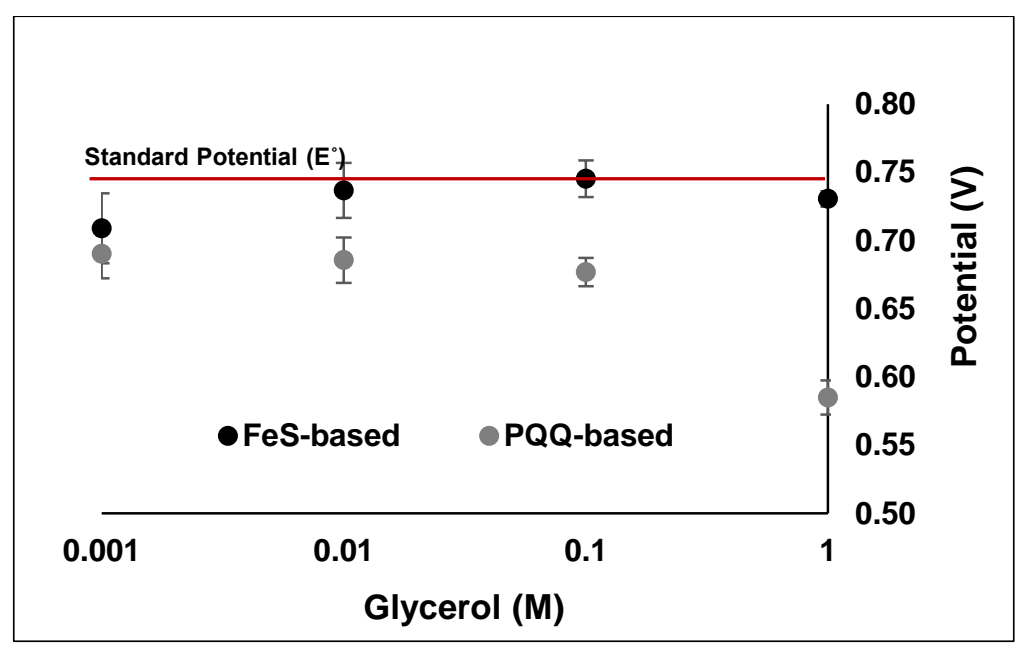

Figure 16. The instantaneous OCV obtained by FeS-based and PQQ-based enzyme electrodes in aqueous glycerol concentrations 0.001 - $1 \mathrm{M}$ containing enzyme stimulants.

It can be observed from Figure 16 that, the instantaneous OCV produced by FeS-based electrodes were significantly higher than that of the PQQ-based electrode. It is inciting to observe that the FeS-based electrode reached the theoretical maximum $\mathrm{E}^{0}$ (half-wave potential) under all glycerol concentrations while the ability of the cell to maintain its 
theoretical potential deteriorated with increasing glycerol concentrations with the conventional PQQ-based electrode.

CVs showing the amperometric response of the FeS-based enzyme electrode in glycerol concentrations ranging from $0-1 \mathrm{M}$ are depicted in Figure 17. FeS-based system shows an increase in anodic peak currents $\left(\left|\mathrm{I}_{\mathrm{a}}\right|\right)$ and cathodic peak currents $\left(\left|\mathrm{I}_{\mathrm{c}}\right|\right)$ at $1.3 \mathrm{~V}$ and 0.665 $\mathrm{V}$ respectively for increasing glycerol concentrations.

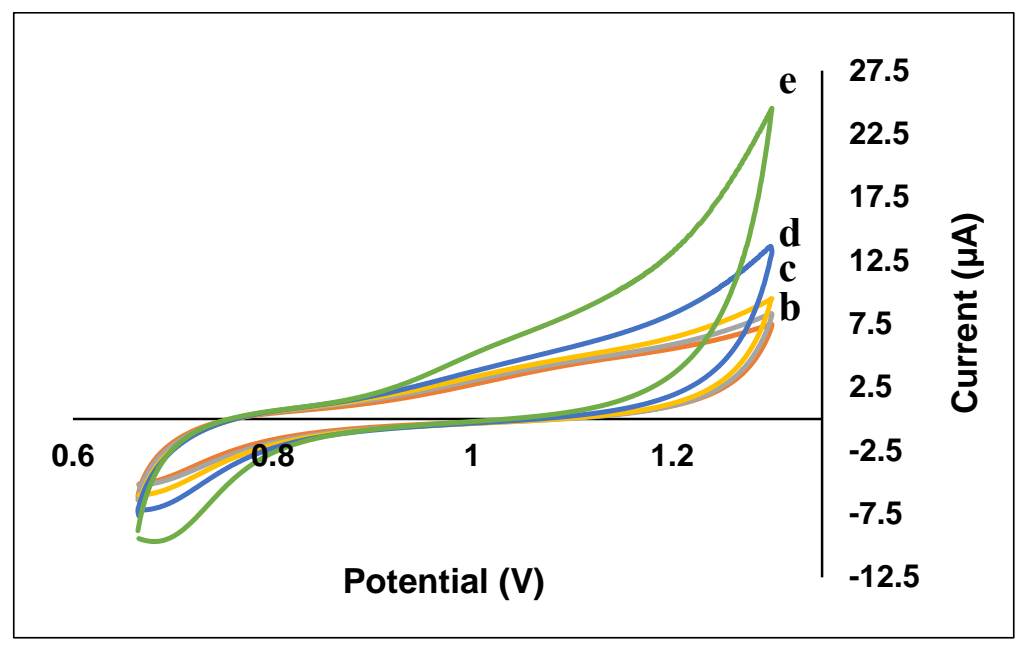

Figure 17. Cyclic voltammograms for FeS-based enzyme electrode in increasing concentrations of glycerol $(\mathrm{a}-\mathrm{0} \mathrm{M}, \mathrm{b}-\mathbf{0 . 0 0 1} \mathrm{M}, \mathrm{c}-\mathbf{0 . 0 1} \mathrm{M}, \mathrm{d}-\mathbf{0 . 1} \mathrm{M}$ and $\mathrm{e}-1 \mathrm{M})$ at scan rate $50 \mathrm{mV} / \mathrm{s}$. 


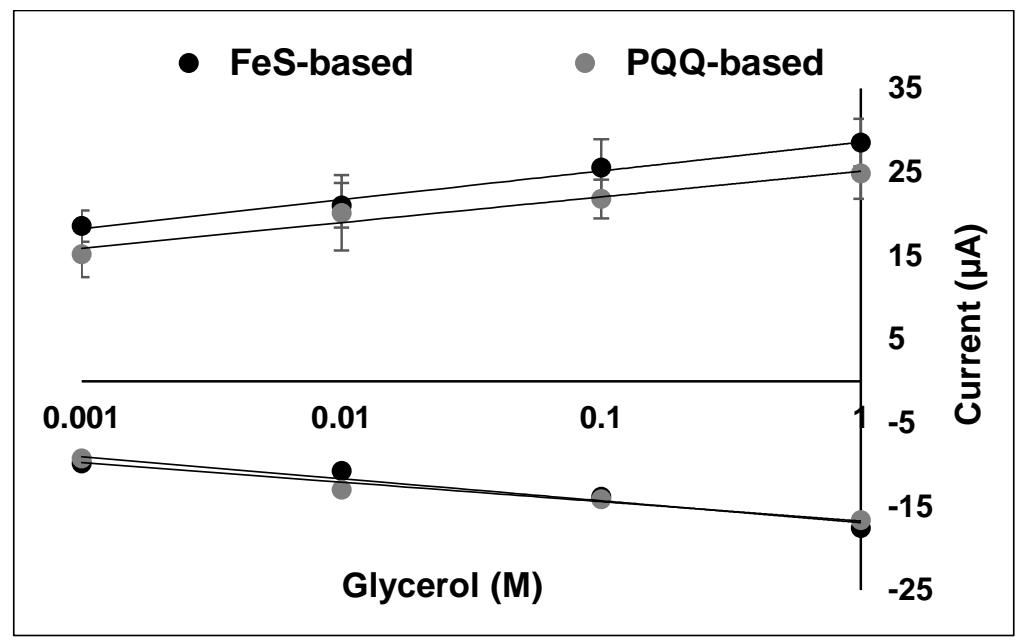

Figure 18. Peak current (Ip) at $1.3 \mathrm{~V}$ and $0.665 \mathrm{~V}$ vs. glycerol concentrations measured by enzymatic electrodes (FeS-based and PQQ-based) derived from CV scans between 0 to $1.5 \mathrm{~V}$ at scan rate $50 \mathrm{mV} / \mathrm{s}$. Note: Fitting equations for $\mathrm{FeS}-$

based $@ 1.3 \mathrm{~V}$ is $\mathrm{y}=1.4969 \ln (\mathrm{x})+28.573, \mathrm{R}^{2}=0.9883$ and PQQ-based is 1.3337ln $(x)+25.092, R^{2}=0.9595 ;$ FeS-based @ $0.665 \mathrm{~V}$ is $\mathrm{y}=-1.139 \ln (\mathrm{x})$ - 16.924, $R^{2}=0.9397$ and $P Q Q-b a s e d$ is $-1.01 \ln (x)-16.734, R^{2}=0.9578$.

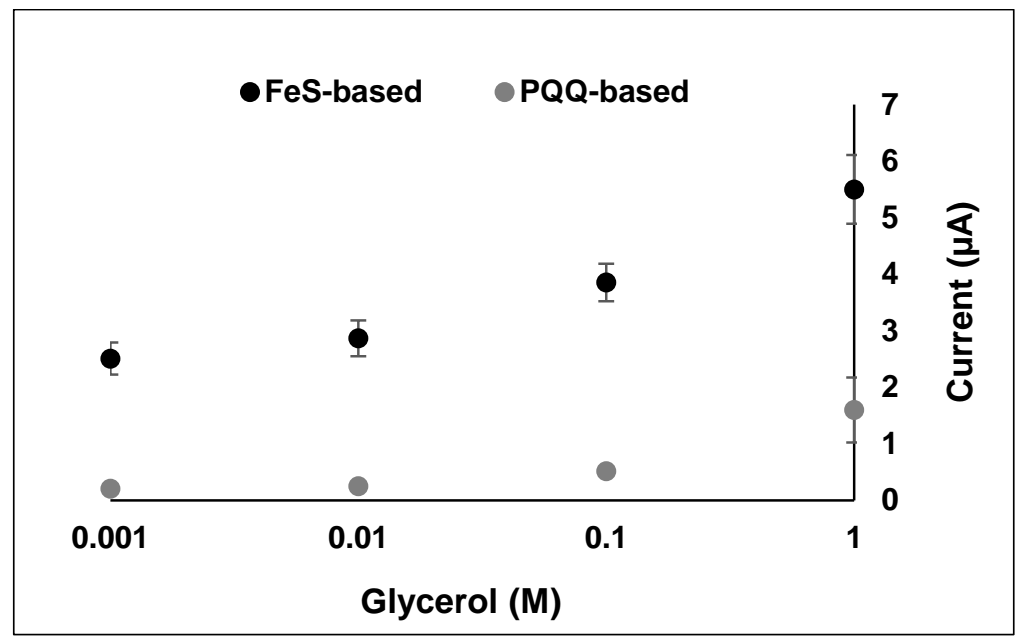

Figure 19. Equilibrated $(60 \mathrm{~s})$ constant potential amperometric measurements of anodic currents for FeS-based and PQQ-based enzyme electrodes in glycerol concentrations between $0.001-1 \mathrm{M}$ at $\mathrm{E}=1.3 \mathrm{~V}$. Note: This analysis indicates how the two electrode systems will behave in a practical situation such as a bio-sensing application. 
Table 2. Percentage increase in current and voltage generated by different methods

\begin{tabular}{|c|c|c|c|}
\hline \multirow{2}{*}{$\begin{array}{c}\text { Glycerol } \\
(\mathbf{M})\end{array}$} & $\begin{array}{c}\text { Cyclic Voltammetry } \\
(\mathbf{0}-\mathbf{1 . 5} \mathbf{~ V )}\end{array}$ & $\begin{array}{c}\text { Constant-potential } \\
\text { Amperometry } \\
(\mathbf{6 0} \mathbf{s} \text { Measurement })\end{array}$ & $\begin{array}{c}\text { OCV } \\
\text { Instantaneous }\end{array}$ \\
\hline 0.001 & $\begin{array}{c}\text { Ip at } \\
\mathbf{1 . 3} \mathbf{~ V}\end{array}$ & $\mathbf{1 . 3} \mathbf{~ V}$ & \\
\hline 0.01 & $23.60 \%$ & $1140.03 \%$ & $2.79 \%$ \\
\hline 0.1 & $6.51 \%$ & $1052.88 \%$ & $7.46 \%$ \\
\hline 1 & $17.20 \%$ & $656.73 \%$ & $10.13 \%$ \\
\hline
\end{tabular}

A correlation plot between glycerol concentration and the peaks currents were developed to compare $\left|\mathrm{I}_{\mathrm{a}}\right|$ and $\left|\mathrm{I}_{\mathrm{c}}\right|$ of Fe-based and PQQ-based electrodes (Figure 18). Apart from having a strong logarithmic correlation with glycerol concentration (between 0.001 and 1 M), FeS-based system showed a remarkable increase in $\left|I_{a}\right|$ when compared with that of the PQQ-based system. $\left|I_{c}\right|$ however did not vary significantly between the two electrode systems. It is important to understand how the two electrode systems will behave in a practical situation, such as in a bio-sensing application, where the electrodes are kept at a constant potential and the peak currents are measured. The constant potential amperometric measurements for the FeS-based and PQQ-based electrodes at $1.3 \mathrm{~V}$ (oxidative) are depicted in Figure 19. Clearly, the peak currents of the FeS-based system outperformed the PQQ based in this instance as well.

A comparison on the actual peak current and OCV differences of the two electrode systems at varying glycerol concentrations is presented in Table 2. It is clear that a 
remarkable, over seven fold, average peak current increase is observed over the glycerol concentrations tested.

Chronoamperograms generated for the enzyme electrodes in glycerol gave a symmetrical oxidative and reductive response (see Figure 20.). The diffusion coefficient was derived from Cottrell plot ( $\mathrm{I} \mathrm{vs} \mathrm{t}^{-1 / 2}$, see Figure 21.) using the equation, $I=\frac{n F A \sqrt{D} C}{\sqrt{\pi t}}$, where, D is the diffusion coefficient $\left(\mathrm{cm}^{2} \mathrm{~s}^{-1}\right), \mathrm{C}$ is the bulk concentration of analyte $\left(\mathrm{mol} . \mathrm{cm}^{-3}\right)$, and $\mathrm{n}, \mathrm{F}$ and $\mathrm{A}$ are number of electrons in redox reaction, Faraday number, and electrode surface area, respectively (Bard \& Faulkner, 1980).

As seen with PQQ-based electrodes, D values of the Fe-based electrodes also correlate with increasing glycerol concentrations as depicted in Figure 22. An average diffusion coefficient of $1.24 \times 10^{-5} \mathrm{~cm}^{2} \mathrm{~s}^{-1}$ for glycerol concentrations $0.001-1 \mathrm{M}$ was obtained with the FeS-based electrode, which is similar with that obtained by the conventional PQQ-based electrode $\left(1.68 \times 10^{-5} \mathrm{~cm}^{2} \mathrm{~s}^{-1}\right)$. As diffusion coefficient is unique for a solute, this study further confirmed that the FeS-based enzyme electrode is sensitive to glycerol. 


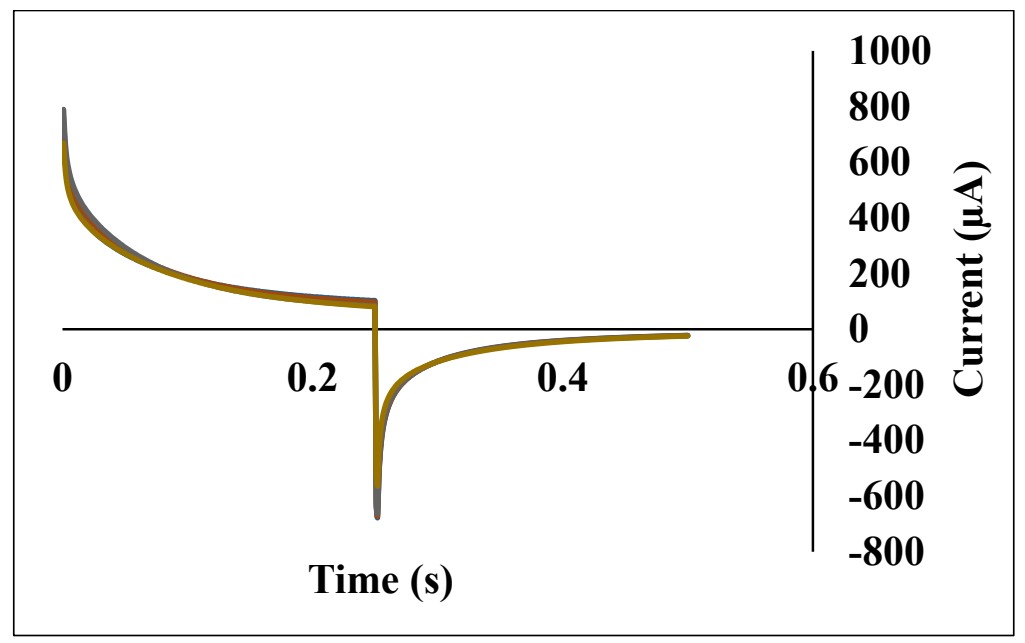

Figure 20. Chronoamperograms for FeS-based enzyme electrode in $0.001-1 \mathrm{M}$ glycerol

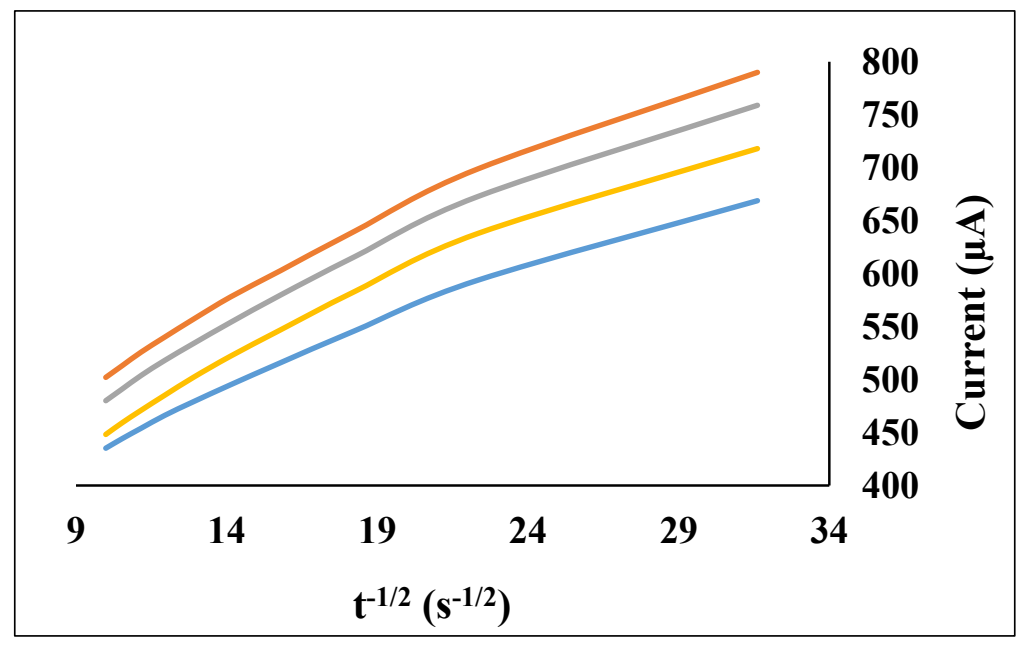

Figure 21. Cottrell plot (I vs t-1/2) obtained from chronoamperograms of FeSbased enzyme electrode in $0.001-1 \mathrm{M}$ glycerol 


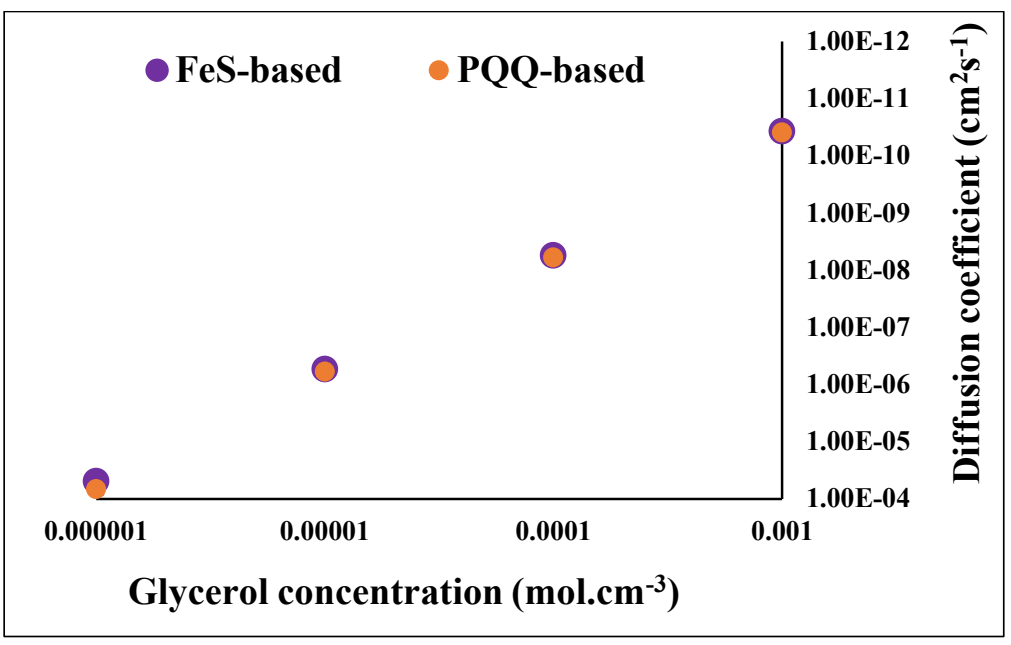

Figure 22. Correlation of bulk concentration and diffusion coefficient. Initial $E=$ $0.665 \mathrm{~V}$ and Final $\mathrm{E}=1.3 \mathrm{~V}$ for this study

\subsection{Conclusion}

The objective of this specific study was to develop and compare the electrochemical response and charge transport characteristics of enzymatic electrodes after direct attachment of glycerol-dehydrogenase/nicotinamide-adenine-dinucleotide (GIDH-NAD $\left.{ }^{+}\right)$ apoenzyme-coenzyme complex to a supporting gold electrode using a novel inorganic iron (II) sulfide (FeS)-based single-molecular-wire and a conventional PQQ based composite wiring system. The open circuit voltage of a glycerol consuming cell developed with conventional PQQ-based electrodes was consistently lower than the standard potential while that with the FeS-based electrodes consistently reached the standard potential due to reduced ohmic losses. When the two electrode systems were interrogated with cyclic voltammetry at glycerol concentrations between $0.001-1 \mathrm{M}$, the FeS-based electrodes consistently gave higher peak currents as compared to the conventional PQQ-based counterparts. A constant potential amperometry study (emulating the use of such 
electrodes for real-world applications) indicated over 10-fold increase in peak currents for lower glycerol concentrations with an average increase of over 7 -fold over the entire range of substrate concentrations tested (i.e., between $0.001-1 \mathrm{M}$ ). This remarkable enhancement of electrical charge transport properties is as a result of: 1) the reduced internal resistance of the enzymatic electrode resulting from the shorter FeS singlemolecular-wire as opposed to the conventional PQQ-based writing system that requires a series of molecules to foster enzyme attachment and 2) the ability of FeS to not only be a single-molecular anchoring agent, but also being able to mediate electron shuttling between $\mathrm{NAD}^{+}$and the supporting electrode. 


\section{CHAPTER V}

\section{CONCLUSIONS}

A novel iron (II) sulfide (FeS) based molecular wiring system was developed for immobilizing glycerol dehydrogenase on a gold electrode surface. Amperometric and potentiometric analyses with glycerol dehydrogenase-based model electrodes confirmed the ability of this single-molecule to remarkably amplify, about ten-fold increase in current and upto $24 \%$ increase in voltage outputs, as compared to electrodes fabricated with the conventional Pyrroloquinoline quinone-based molecular wiring system. FeS achieves the dual purpose of anchoring the enzyme to the gold electrode while also mediating electron shuttling between coenzyme and the electrode surface - emulating the first link in the mitochondrial electron transport chain. This duel functionality allows usage of a singlemolecular wire to foster electrical communication between the enzyme and the electrode instead of the conventional multi-molecular wiring system and in turn reducing the internal resistance of the electrode. The resulting increase in current/voltage response opens up a wide range of possibilities for developing efficient bio-electrodes for bioelectronics applications. 


\subsection{Recommendations for Future Studies}

1. To conduct stability and interference studies of the enzyme electrodes for real-world sensing and biofuel cell applications.

2. To examine the stability of $\mathrm{Fe}-\mathrm{NAD}^{+}$coordination.

3. To conduct studies on the enzymatic stimulants in order to understand their role in the system apart from improving specificity of the enzyme GIDH.

4. To investigate on the applicability of the novel wiring scheme for other redox enzymes.

5. To perform studies on other forms of iron-sulfur clusters, especially nano-sized surrogates. 


\section{REFERENCES}

Aelterman, P., Versichele, M., Marzorati, M., Boon, N., \& Verstraete, W. (2008). Loading rate and external resistance control the electricity generation of microbial fuel cells with different three-dimensional anodes. Bioresource Technology, 99(18), 88958902. doi: http://dx.doi.org/10.1016/j.biortech.2008.04.061

Alkire, R. C., Kolb, D. M., Lipkowski, J., \& Ross, P. N. (2013). Bioelectrochemistry: Fundamentals, Applications and Recent Developments (Vol. 26): John Wiley \& Sons.

Aston, W. J., \& Turner, A. P. F. (1984). Biosensors and biofuel cells. Biotechnology and genetic engineering reviews, 1(1), 89-120.

Barbir, F. (2004). PEM Fuel Cells: Theory and Practice. 2005. Editorial ELSEVIER, 433.

Bard, A. J., \& Faulkner, L. R. (1980). Electrochemical methods: fundamentals and applications (Vol. 2): Wiley New York.

Beinert, H., Holm, R. H., \& Münck, E. (1997). Iron-sulfur clusters: nature's modular, multipurpose structures. Science, 277(5326), 653-659.

Bennetto, H. P. (1984), in Life Chemistry Reports, vols., 2, no. 4, Michelson, A. M., and Bannister, J. V., eds., Harwood Academic, London, pp. 363-453.

Bennetto, H. P. (1990). Electricyt generation by Microorganism. Biotechnology Education, 1, 163-168.

Brzóska, K., Meczynska, S., \& Kruszewski, M. (2006). Iron-sulfur cluster proteins: electron transfer and beyond. Acta Biochimica Poloica-English Edition-, 53(4), 685 . 
Busalmen, J. P., Esteve-Nuñez, A., \& Feliu, J. M. (2008). Whole cell electrochemistry of electricity-producing microorganisms evidence an adaptation for optimal exocellular electron transport. Environmental science \& technology, 42(7), 24452450.

Chaudhuri, S. K., \& Lovley, D. R. (2003). Electricity generation by direct oxidation of glucose in mediatorless microbial fuel cells. Nature biotechnology,21(10), 12291232.

Chen, A. K., Starzmann, J. A., \& Liu, C. C. (1982). Potentiometric quantitation of glycerol using immobilized glycerol dehydrogenase. Biotechnology and Bioengineering, 24(4), 971-975. doi: 10.1002/bit.260240416

Cohen, B. (1931). The bacterial culture as an electrical half-cell. J. Bacteriol, 21(1), 1819.

Cole, K. S. (1968). Membranes, ions, and impulses: a chapter of classical biophysics (Vol. 5). Univ of California Press.

Cooney, M. J., Roschi, E., Marison, I. W., Comminellis, C., \& von Stockar, U. (1996). Physiologic studies with the sulfate-reducing bacterium Desulfovibrio desulfuricans: Evaluation for use in a biofuel cell. Enzyme and microbial technology, 18(5), 358-365.

Crittenden, S. R., Sund, C. J., \& Sumner, J. J. (2006). Mediating Electron Transfer from Bacteria to a Gold Electrode via a Self-Assembled Monolayer. Langmuir, 22(23), 9473-9476. doi: 10.1021/la061869j

Delaney, G. M., Bennetto, H. P., Mason, J. R., Roller, S. D., Stirling, J. L. and Thurston, C. F. . (1984 ). Electron-transfer coupling in microbial fuel-cells 2. Performance of fuel-cells containing selected microorganism mediator substrate combinations. J. Chem. Technol. Biotechnol. , 34(1), 13-27.

Ding, S.-J., Chang, B.-W., Wu, C.-C., Lai, M.-F., \& Chang, H.-C. (2005). Impedance spectral studies of self-assembly of alkanethiols with different chain lengths using 
different immobilization strategies on Au electrodes. Analytica Chimica Acta, 554(1-2), 43-51. doi: http://dx.doi.org/10.1016/j.aca.2005.08.046

Dowdy, C. E., \& Leopold, M. C. (2010). Enhanced electrochemistry of nanoparticleembedded polyelectrolyte films: Interfacial electronic coupling and distance dependence. Thin Solid Films, 519(2), 790-796.

Eftekhari, A. (2001). Glycerol biosensor based on glycerol dehydrogenase incorporated into polyaniline modified aluminum electrode using hexacyanoferrate as mediator. Sensors and Actuators B: Chemical, 80(3), 283-289. doi: http://dx.doi.org/10.1016/S0925-4005(01)00916-9

Falk, M., Blum, Z., \& Shleev, S. (2012). Direct electron transfer based enzymatic fuel cells. Electrochimica Acta, 82(0), 191-202. doi: http://dx.doi.org/10.1016/j.electacta.2011.12.133

Fan, Y., Xu, S., Schaller, R., Jiao, J., Chaplen, F., \& Liu, H. (2011). Nanoparticle decorated anodes for enhanced current generation in microbial electrochemical cells. Biosensors and Bioelectronics, 26(5), 1908-1912. doi: http://dx.doi.org/10.1016/j.bios.2010.05.006

Feng, C., Li, F., Liu, H., Lang, X., \& Fan, S. (2010). A dual-chamber microbial fuel cell with conductive film-modified anode and cathode and its application for the neutral electro-Fenton process. Electrochimica Acta, 55(6), 2048-2054. doi: http://dx.doi.org/10.1016/j.electacta.2009.11.033

Fischer, L. M., Tenje, M., Heiskanen, A. R., Masuda, N., Castillo, J., Bentien, A., . . . Boisen, A. (2009). Gold cleaning methods for electrochemical detection applications. Microelectronic Engineering, 86(4-6), 1282-1285. doi: http://dx.doi.org/10.1016/j.mee.2008.11.045

Fraiwan, A., Call, D. F., \& Choi, S. (2014). Bacterial growth and respiration in laminar flow microbial fuel cells. Journal of Renewable and Sustainable Energy, 6(2), -. doi: doi:http://dx.doi.org/10.1063/1.4873399 
Gil, G. C., Chang, I. S., Kim, B. H., Kim, M., Jang, J. K., Park, H. S., \& Kim, H. J. (2003). Operational parameters affecting the performance of a mediator-less microbial fuel cell. Biosens. Bioelectron. , 18(4), 327-334.

Gooding, J. J., Wibowo, R., Liu, Yang, W., Losic, D., Orbons, S., . . Hibbert, D. B. (2003). Protein Electrochemistry Using Aligned Carbon Nanotube Arrays. Journal of the American Chemical Society, 125(30), 9006-9007. doi: 10.1021/ja035722f

Gorby, Y. A., Yanina, S., McLean, J. S., Rosso, K. M., Moyles, D., Dohnalkova, A., . . . Kim, K. S. (2006). Electrically conductive bacterial nanowires produced by Shewanella oneidensis strain MR-1 and other microorganisms. Proceedings of the National Academy of Sciences, 103(30), 11358-11363.

Goriushkina, T., Shkotova, L., Gayda, G., Klepach, H., Gonchar, M., Soldatkin, A., \& Dzyadevych, S. (2010). Amperometric biosensor based on glycerol oxidase for glycerol determination. Sensors and Actuators B: Chemical, 144(2), 361-367.

Gunawardena, A., Fernando, S., \& To, F. (2008). Performance of a yeast-mediated biological fuel cell. International journal of molecular sciences, 9(10), 1893-1907.

Gunawardena, D. A., Fernando, S. D., Fernando, T. J., \& Perera, O. P. (2012). Performance analysis of a proton exchange membraneless biological fuel cell based on lactate dehydrogenase. Biological Engineering Transactions, 5(1), 3346.

Heller, A. (1992). Electrical connection of enzyme redox centers to electrodes. The Journal of Physical Chemistry, 96(9), 3579-3587. doi: 10.1021/j100188a007

Higgins, S. R., Foerster, D., Cheung, A., Lau, C., Bretschger, O., Minteer, S. D., . . . Cooney, M. J. (2011). Fabrication of macroporous chitosan scaffolds doped with carbon nanotubes and their characterization in microbial fuel cell operation. Enzyme and Microbial Technology, 48(6-7), 458-465. doi: http://dx.doi.org/10.1016/j.enzmictec.2011.02.006

Ishige, Y., Shimoda, M., \& Kamahori, M. (2009). Extended-gate FET-based enzyme sensor with ferrocenyl-alkanethiol modified gold sensing electrode. Biosensors 
and Bioelectronics, 24(5), 1096-1102. doi: http://dx.doi.org/10.1016/j.bios.2008.06.012

Johnson, D. C., Dean, D. R., Smith, A. D., \& Johnson, M. K. (2005). Structure, function, and formation of biological iron-sulfur clusters. Anпи. Rev. Biochem., 74, 247-281.

Kalathil, S., Hoa, A., Shim, J., Mansoob, M., Lee, J., \& Cho, M. H. (2013). Enhanced Performance of a Microbial Fuel Cell Using CNT/MnO2 Nanocomposites as a Bioanode Materials. Journal of nanoscience and nanotechnology, 13, 7712-7716.

Katz, E., Shipway, A. N., \& Willner, I. (2010). Biochemical fuel cells Handbook of Fuel Cells: John Wiley \& Sons, Ltd.

Keneth, L. (1966). Biochemical Fuel Cells. Paper presented at the Symposium on Bioelectrochemistry of Microorganisms.

Kim, H. J., Park, H. S., Hyun, M. S., Chang, I. S., Kim, M., \& Kim, B. H. (2002). A mediator-less microbial fuel cell using a metal reducing bacterium, Shewanella putrefaciens. Enzyme and Microbial Technology, 30(2), 145-152. doi: http://dx.doi.org/10.1016/S0141-0229(01)00478-1

Kumar, G. G., Sarathi, V. G. S., \& Nahm, K. S. (2013). Recent advances and challenges in the anode architecture and their modifications for the applications of microbial fuel cells. Biosensors and Bioelectronics, 43(0), 461-475. doi: http://dx.doi.org/10.1016/j.bios.2012.12.048

LaBelle, E., \& Bond, D. (2009). Cyclic voltammetry for the study of microbial electron transfer at electrodes. Bioelectrochemical systems: from extracellular electron transfer to biotechnological application, 137-152.

Lapenaite, I., Kurtinaitiene, B., Razumiene, J., Laurinavicius, V., Marcinkeviciene, L., Bachmatova, I., ... Ramanavicius, A. (2005). Properties and analytical application of PQQ-dependent glycerol dehydrogenase from Gluconobacter sp. 33. Analytica Chimica Acta, 549(1), 140-150. 
Larminie, J., Dicks, A., \& McDonald, M. S. (2003). Fuel cell systems explained(Vol. 2). New York: Wiley.

Leech, D., Kavanagh, P., \& Schuhmann, W. (2012). Enzymatic fuel cells: Recent progress. Electrochimica Acta, 84(0), 223-234. doi: http://dx.doi.org/10.1016/j.electacta.2012.02.087

Li, X., He, J., Hihath, J., Xu, B., Lindsay, S. M., \& Tao, N. (2006). Conductance of Single Alkanedithiols: Conduction Mechanism and Effect of Molecule-Electrode Contacts. Journal of the American Chemical Society, 128(6), 2135-2141. doi: $10.1021 / \mathrm{ja} 057316 \mathrm{x}$

Liang, P., Wang, H., Xia, X., Huang, X., Mo, Y., Cao, X., \& Fan, M. (2011). Carbon nanotube powders as electrode modifier to enhance the activity of anodic biofilm in microbial fuel cells. Biosensors and Bioelectronics, 26(6), 3000-3004. doi: http://dx.doi.org/10.1016/j.bios.2010.12.002

Lies, D. P., Hernandez, M. E., Kappler, A., Mielke, R. E., Gralnick, J. A., \& Newman, D. K. (2005). Shewanella oneidensis MR-1 uses overlapping pathways for iron reduction at a distance and by direct contact under conditions relevant for biofilms. Applied and environmental microbiology, 71(8), 4414-4426.

Liu, H., Cheng, S., \& Logan, B. E. (2004). Production of Electricity from Acetate or Butyrate Using a Single-Chamber Microbial Fuel Cell. Environmental Science \& Technology, 39(2), 658-662. doi: 10.1021/es048927c

Lloyd, G. E. (1987). Atomic number and crystallographic contrast images with the SEM: a review of backscattered electron techniques. Mineralogical Magazine, 51(359), 3-19.

Logan, B., Cheng, S., Watson, V., \& Estadt, G. (2007). Graphite Fiber Brush Anodes for Increased Power Production in Air-Cathode Microbial Fuel Cells. Environmental Science \& Technology, 41(9), 3341-3346. doi: 10.1021/es062644y 
Logan, B. E., Hamelers, B., Rozendal, R., Schröder, U., Keller, J., Freguia, S., . . Rabaey, K. (2006). Microbial fuel cells: methodology and technology. Environmental science \& technology, 40(17), 5181-5192.

Lovley, D. R., Phillips, E., Lonergan, D. J., \& Widman, P. K. (1995). Fe (III) and S0 reduction by Pelobacter carbinolicus. Applied and environmental microbiology, 61(6), 2132-2138.

Lu, X., Zhang, Y., Zhang, M., Chen, Y., \& Kang, J. (2007). Electrochemical and microscopic studies of surface-confined DNA. Journal of Solid State Electrochemistry, 11(4), 496-504. doi: 10.1007/s10008-006-0186-z

Luckarift, H. R., Sizemore, S. R., Farrington, K. E., Roy, J., Lau, C., Atanassov, P. B., \& Johnson, G. R. (2012). Facile Fabrication of Scalable, Hierarchically Structured Polymer/Carbon Architectures for Bioelectrodes. ACS Applied Materials \& Interfaces, 4(4), 2082-2087. doi: 10.1021/am300048v

Luo, H., Liu, G., Zhang, R., \& Cao, L. (2009). [Isolation and characterization of electrochemical active bacterial Pseudomonas aeruginosa strain RE7]. Huan jing ke xue = Huanjing kexue/[bian ji, Zhongguo ke xue yuan huan jing ke xue wei yuan hui" Huan jing ke xue" bian ji wei yuan hui.], 30(7), 2118-2123.

Mahadevan, A., Gunawardena, D. A., \& Fernando, S. (2014). Biochemical and Electrochemical Perspectives of the Anode of a Microbial Fuel Cell, Technology and Application of Microbial Fuel Cells, InTech, DOI: 10.5772/58755.

Malvankar, N. S., \& Lovley, D. R. (2012). Microbial nanowires: a new paradigm for biological electron transfer and bioelectronics. ChemSusChem, 5(6), 1039-1046.

Malvankar, N. S., Vargas, M., Nevin, K. P., Franks, A. E., Leang, C., Kim, B.-C., . . . Johnson, J. P. (2011). Tunable metallic-like conductivity in microbial nanowire networks. Nature Nanotechnology, 6(9), 573-579.

Marcus, R. A., \& Sutin, N. (1985). Electron transfers in chemistry and biology. Biochimica et Biophysica Acta (BBA)-Reviews on Bioenergetics, 811(3), 265-322. 
Migneault, I., Dartiguenave, C., Bertrand, M. J., \& Waldron, K. C. (2004). Glutaraldehyde: behavior in aqueous solution, reaction with proteins, and application to enzyme crosslinking. Biotechniques, 37(5), 790-806.

Mink, J. E., Rojas, J. P., Logan, B. E., \& Hussain, M. M. (2012). Vertically Grown Multiwalled Carbon Nanotube Anode and Nickel Silicide Integrated High Performance Microsized (1.25 $\mu \mathrm{L}$ ) Microbial Fuel Cell. Nano Letters, 12(2), 791795. doi: $10.1021 / \mathrm{nl} 203801 \mathrm{~h}$

Mitchell, W. (1963). Fuel cells: Academic press Inc. NewYork.

Nedović, V., \& Willaert, R. (2006). Applications of cell immobilisation biotechnology: Springer.

Park, D. H., \& Zeikus, J. G. (2003). Improved fuel cell and electrode designs for produsing electricity from microbial degradation. Bioenergy and Biotechnology, 81(3), 348355 .

Potter, M. C. (1908). Bacteria as agents in the oxidation of amorphous carbon.Proceedings of the Royal Society of London. Series B, Containing Papers of a Biological Character, 239-259.

Prasad, D., Arun, S., Murugesan, M., Padmanaban, S., Satyanarayanan, R. S., Berchmans, S., \& Yegnaraman, V. (2007). Direct electron transfer with yeast cells and construction of a mediatorless microbial fuel cell. Biosensors and Bioelectronics, 22(11), 2604-2610. doi: http://dx.doi.org/10.1016/j.bios.2006.10.028

Prodromidis, M. I., \& Karayannis, M. I. (2002). Enzyme based amperometric biosensors for food analysis. Electroanalysis, 14(4), 241.

Rabaey, K., Clauwaert, P., Aelterman, P., \& Verstraete, W. (2005). Tubular Microbial Fuel Cells for Efficient Electricity Generation. Environmental Science \& Technology, 39(20), 8077-8082. doi: 10.1021/es050986i 
Radoi, A., \& Compagnone, D. (2009). Recent advances in NADH electrochemical sensing design. Bioelectrochemistry, 76(1-2), 126-134. doi: http://dx.doi.org/10.1016/j.bioelechem.2009.06.008

Ramachandran, G. K., Tomfohr, J. K., Li, J., Sankey, O. F., Zarate, X., Primak, A., . . . Lindsay, S. M. (2003). Electron Transport Properties of a Carotene Molecule in a Metal-(Single Molecule)-Metal Junction. The Journal of Physical Chemistry B, 107(25), 6162-6169. doi: 10.1021/jp0343786

Reardon, P. N., \& Mueller, K. T. (2013). Structure of the Type IVa Major Pilin from the Electrically Conductive Bacterial Nanowires of Geobacter sulfurreducens. Journal of Biological Chemistry, 288(41), 29260-29266. doi: 10.1074/jbc.M113.498527

Reguera, G., McCarthy, K. D., Mehta, T., Nicoll, J. S., Tuominen, M. T., \& Lovley, D. R. (2005). Extracellular electron transfer via microbial nanowires. Nature, 435(7045), 1098-1101.

Rhoads, A., Beyenal, H., \& Lewandowski, Z. (2005). Microbial Fuel Cell using anaerobic respiration as an anodic reaction and biomineralized manganese as a cathodic reactant. Environmental Science and Technology, 39, 4666-4671.

Roller, S. D., Bennetto, H. P., Delany, G. M., Mason, J. R., Sterling, J. L., \& Thurston, C. F. (1984). Electron transfer coupling in microbial fuel-cells 1. Comparison of redox-mediator reduction rates and respiratory rates of bacteria. J. Chemical Technology Biotechnology, 34B, 3-12.

Ronkainen, N. J., Halsall, H. B., \& Heineman, W. R. (2010). Electrochemical biosensors. Chemical Society Reviews, 39(5), 1747-1763.

Rozendal, R. A., Hamelers, H. V., Rabaey, K., Keller, J., \& Buisman, C. J. (2008). Towards practical implementation of bioelectrochemical wastewater treatment. Trends in biotechnology, 26(8), 450-459. 
Schmidt, H.-L., \& Schuhmann, W. (1996). Reagentless oxidoreductase sensors. Biosensors and Bioelectronics, 11(1-2), 127-135. doi: http://dx.doi.org/10.1016/0956-5663(96)83720-1

Scholz, F., \& Schroder, U. (2003). Bacterial Batteries. Nature Biotechnology, 21(10), 1151-1152.

Schröder, U. (2007). Anodic electron transfer mechanisms in microbial fuel cells and their energy efficiency. Physical Chemistry Chemical Physics, 9(21), 2619-2629.

Schröder, U., Niessen, J. and Scholz, F. . (2003). A generation of microbial fuel cells with current outputs boosted by more than one order of magnitude. . Angewandte Chemie International Edition 42(25), 2880-2883.

Sekoai, P. T., \& Gueguim Kana, E. B. (2014). Semi-pilot scale production of hydrogen from Organic Fraction of Solid Municipal Waste and electricity generation from process effluents. Biomass and Bioenergy, 60(0), 156-163. doi: http://dx.doi.org/10.1016/j.biombioe.2013.11.008

Straub, K. L., \& Schink, B. (2004). Ferrihydrite-dependent growth of Sulfurospirillum deleyianum through electron transfer via sulfur cycling. Applied and environmental microbiology, 70(10), 5744-5749.

Tender, L. M., Reimers, C. E., Stecher, H. A., Holms, D. E., Bond, D. R., Lowy, D. A., . .. Lovely, D. R. (2002). Harnesssing microbially generated power on the seafloor. Natural Biotechnology, 20(8), 821-825.

Thygesen, A., Poulsen, F. W., Min, B., Angelidaki, I., \& Thomsen, A. B. (2009). The effect of different substrates and humic acid on power generation in microbial fuel cell operation. Bioresource Technology, 100(3), 1186-1191. doi: http://dx.doi.org/10.1016/j.biortech.2008.07.067

Torres, C. I., Marcus, A. K., Lee, H.-S., Parameswaran, P., Krajmalnik-Brown, R., \& Rittmann, B. E. (2010). A kinetic perspective on extracellular electron transfer by anode-respiring bacteria. FEMS microbiology reviews, 34(1), 3-17. doi: 10.1111/j.1574-6976.2009.00191.x 
Tse, D. C.-S., \& Kuwana, T. (1978). Electrocatalysis of dihydronicotinamide adenosine diphosphate with quinones and modified quinone electrodes. Analytical chemistry, 50(9), 1315-1318. doi: 10.1021/ac50031a030

Vargas, I. T., Albert, I. U., \& Regan, J. M. (2013). Spatial distribution of bacterial communities on volumetric and planar anodes in single-chamber air-cathode microbial fuel cells. Biotechnology and Bioengineering, 110(11), 3059-3062. doi: 10.1002/bit.24949

Wang, H.-Y., \& Su, J.-Y. (2013). Membraneless microfluidic microbial fuel cell for rapid detection of electrochemical activity of microorganism. Bioresource Technology, 145(0), 271-274. doi: http://dx.doi.org/10.1016/j.biortech.2013.01.014

Wang, H., Wang, G., Ling, Y., Qian, F., Song, Y., Lu, X., . . Li, Y. (2013). High power density microbial fuel cell with flexible 3D graphene-nickel foam as anode. Nanoscale, 5(21), 10283-10290. doi: 10.1039/C3NR03487A

White, A., Handler, P., \& Smith, E. L. (1973). Principles of Biochemistry: McGraw Hill.

Willner, B., Katz, E., \& Willner, I. (2006). Electrical contacting of redox proteins by nanotechnological means. Current opinion in biotechnology, 17(6), 589-596.

Willner, I., KAtz, E., Patolsky, F., \& Buckmann, F. A. (1998). Biofuel cell based on glucose oxidase and microperoxidase-11 monolayer functionalized electrode. $J$. Chemical Soc.-Perkin Trans., 2(8), 1817-1822.

Wingard Jr, L. B., Shaw, C. H., \& Castner, J. F. (1982). Bioelectrochemical fuel cells. Enzyme and Microbial Technology, 4(3), 137-142.

Wong, C.-H., \& Whitesides, G. M. (1994). Enzymes in synthetic organic chemistry (Vol. 12): Academic Press.

Xiao, Y., Patolsky, F., Katz, E., Hainfeld, J. F., \& Willner, I. (2003). " Plugging into enzymes": nanowiring of redox enzymes by a gold nanoparticle. Science, 299(5614), 1877-1881. 
Xie, X., Hu, L., Pasta, M., Wells, G. F., Kong, D., Criddle, C. S., \& Cui, Y. (2010). ThreeDimensional Carbon Nanotube-Textile Anode for High-Performance Microbial Fuel Cells. Nano Letters, 11(1), 291-296. doi: 10.1021/n1103905t

Xu, S., Liu, H., Fan, Y., Schaller, R., Jiao, J., \& Chaplen, F. (2012). Enhanced performance and mechanism study of microbial electrolysis cells using Fe nanoparticledecorated anodes. Applied Microbiology and Biotechnology, 93(2), 871-880. doi: 10.1007/s00253-011-3643-2

Yamazaki, S.-i., Kano, K., Ikeda, T., Isawa, K., \& Kaneko, T. (1999). Role of 2-amino-3carboxy-1,4-naphthoquinone, a strong growth stimulator for bifidobacteria, as an electron transfer mediator for $\mathrm{NAD}(\mathrm{P})+$ regeneration in Bifidobacterium longum. Biochimica et Biophysica Acta (BBA) - General Subjects, 1428(2-3), 241-250. doi: http://dx.doi.org/10.1016/S0304-4165(99)00098-7

Yong, Y.-C., Dong, X.-C., Chan-Park, M. B., Song, H., \& Chen, P. (2012). Macroporous and Monolithic Anode Based on Polyaniline Hybridized Three-Dimensional Graphene for High-Performance Microbial Fuel Cells. ACS Nano, 6(3), 23942400. doi: 10.1021/nn204656d

Yuan, Y., \& Kim, S. (2008). Improved performance of a microbial fuel cell with polypyrrole/carbon black composite coated carbon paper anodes. Bull. Korean Chem. Soc, 29(7), 1345.

Zayats, M., Katz, E., \& Willner, I. (2002). Electrical Contacting of Flavoenzymes and NAD(P)+-Dependent Enzymes by Reconstitution and Affinity Interactions on Phenylboronic Acid Monolayers Associated with Au-Electrodes. Journal of the American Chemical Society, 124(49), 14724-14735. doi: 10.1021/ja027919y

Zebda, A., Gondran, C., Le Goff, A., Holzinger, M., Cinquin, P., \& Cosnier, S. (2011). Mediatorless high-power glucose biofuel cells based on compressed carbon nanotube-enzyme electrodes. Nat Commun, 2, 370. doi: http://www.nature.com/ncomms/journal/v2/n6/suppinfo/ncomms1365_S1.html

Zhang, X., Ju, H., \& Wang, J. (2011). Electrochemical sensors, biosensors and their biomedical applications: Academic Press. 
Zhao, Y., Nakanishi, S., Watanabe, K., \& Hashimoto, K. (2011). Hydroxylated and aminated polyaniline nanowire networks for improving anode performance in microbial fuel cells. Journal of Bioscience and Bioengineering, 112(1), 63-66. doi: http://dx.doi.org/10.1016/j.jbiosc.2011.03.014

Zhou, M., Chi, M., Wang, H., \& Jin, T. (2012). Anode modification by electrochemical oxidation: A new practical method to improve the performance of microbial fuel cells. Biochemical Engineering Journal, 60(0), 151-155. doi: http://dx.doi.org/10.1016/j.bej.2011.10.014

Zhu, N., Chen, X., Zhang, T., Wu, P., Li, P., \& Wu, J. (2011). Improved performance of membrane free single-chamber air-cathode microbial fuel cells with nitric acid and ethylenediamine surface modified activated carbon fiber felt anodes. Bioresource Technology, 102(1), $422-426$.

doi: http://dx.doi.org/10.1016/j.biortech.2010.06.046

Zhu, Z., Sun, F., Zhang, X., \& Zhang, Y. H. P. (2012). Deep oxidation of glucose in enzymatic fuel cells through a synthetic enzymatic pathway containing a cascade of two thermostable dehydrogenases. Biosensors and Bioelectronics, 36(1), 110115. doi: http://dx.doi.org/10.1016/j.bios.2012.04.001 


\section{APPENDIX}

\section{Literature Review: Biochemical and Electrochemical Perspectives of the Anode of a Microbial Fuel Cell*}

\section{Introduction}

\subsection{History of biofuel cell}

The statement "Perhaps the most refined fuel cell system today is the human body, a mechanism that catalytically burns food (fuel) in an electrolyte to produce energy, some of which is electrical" highlights the connection between the living organisms and electricity (Keneth, 1966; Mitchell, 1963). With the experiment conducted using a frog leg, Biologist Lugi Galvani in 1780's proved that electrical energy and biology have a close connection to each other (Cole, 1972). Michael Cresse Potter, a Botany professor also demonstrated that living organisms can generate voltage and deliver current (Potter, 1910).

The term "fuel cell" has been in use for over a century. Despite some uncertainty about who first fabricated one, credits of designing and experimenting with first fuel cells go to both Sir William Grove (1839) and the Swiss scientist Christian F. Shoenbein (1868). In

* Reprinted with permission from Technology and Application of Microbial Fuel Cells (Chapter, Biochemical and Electrochemical Perspectives of the Anode of a Microbial Fuel Cell, ISBN: 978-953-51-1627-1), by Aishwarya Mahadevan, Duminda A. Gunawardena and Sandun Fernando (2014), InTech, Europe, Copyright [2014] by InTech. 
early $19^{\text {th }}$ century, different organisms like bacteria, algae, and yeast were considered for this research. With the advent of the space race, considerable attention was given to energy generation form recycled waste which in turn ignited interest in microbial fuel cell research. Then, during the sixties and in the early seventies, fuel cell related research accelerated as a consequence of the increase in oil prices and has sustained momentum to date. (Cohen, 1931; Wingard, Shaw, Castner, \& 1982). The time lines of fuel cell development are shown in the Figure A1.

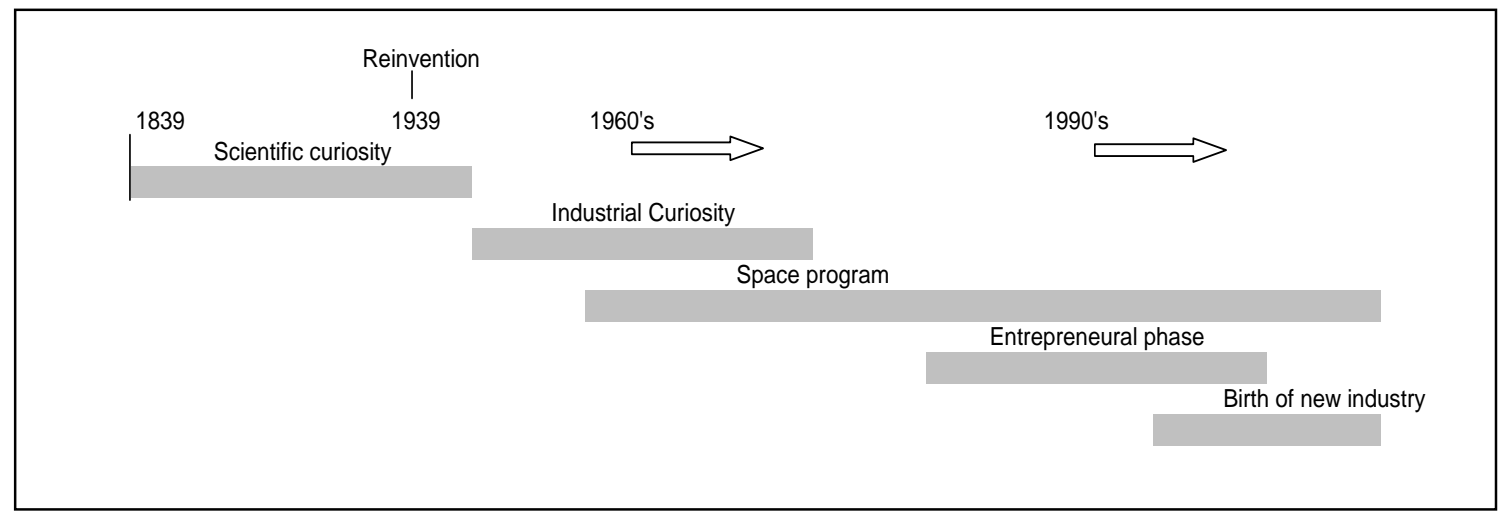

Figure A1. The time line of the fuel cell development(Barbir, 2005)

\subsection{Types of Fuel Cells}

Fuel cells could be broadly categorized into abiotic fuel cells of which the fuel cell components do not comprise any biological material and biotic or biological fuel cells which comprises living organisms or biological material (such as enzymes or derivatives). The primary types of abiotic fuel cells grouped according to the electrolyte used are shown in Table A1. 
Table A1. Different types of commonly known inorganic fuel cells (Barbir, 2005).

\begin{tabular}{|l|l|}
\hline Type & Features \\
\hline Alkaline fuel cells (AFC) & $\begin{array}{l}\text { Uses } \mathrm{KOH} \text { as the electrolyte and electro- } \\
\text { catalysts such as Ni, Ag, metal oxides. }\end{array}$ \\
\hline $\begin{array}{l}\text { Polymer electrolyte membrane fuel cells } \\
\text { (PEMFC) }\end{array}$ & $\begin{array}{l}\text { Usese a proton conductive polymer } \\
\text { membrane as the electrolyte and Pt as the } \\
\text { catalyst }\end{array}$ \\
\hline Phosphoric acid fuel cells (PAFC) & $\begin{array}{l}\text { Uses concentrated phosphoric acid as the } \\
\text { electrolyte and Pt as the catalyst }\end{array}$ \\
\hline Molten carbonate fuel cells (MCFC) & $\begin{array}{l}\text { Has a combination of alkali metals (Li, K, } \\
\text { or Na ) }\end{array}$ \\
\hline Solid oxide fuel cells (SOFC) & $\begin{array}{l}\text { Uses non-porous metal oxide(s) as the } \\
\text { electrolyte }\end{array}$ \\
\hline
\end{tabular}

The biological fuel cell (BFC) can be categorized into two main areas:

(1) Microbial fuel cells (MFC)

(2) Enzymatic fuel cells (EFC)

The biological fuel cells (BFC) use enzymes or microorganisms as catalysts. In a microbial fuel cell, the oxidation reactions that are catalyzed by microbes; alternatively, when the catalyst is an enzyme, the cell is called as an enzymatic fuel cell. While both microorganisms and enzymes catalyze oxidative reactions that takes place at the anode, only enzymes (sometime coupled with inorganic catalysts) are used in the cathode. Biological fuel cells utilize organic substrates (such as sugars and alcohols) and operate at mild temperature environments where biological activity is optimal. For example, the catalyst used in a microbial fuel cell could simply be an organism like Baker's yeast that feed on simple sugars or an advanced species like $R$. ferrireducens (Aston \& F, 1984; Bennetto, 1984, 1990) that thrive on more complex substrates. 


\subsection{Different categories of Microbial Fuel Cells}

Various types of MFC designs have been developed of which five main categories are common:

1) Uncoupled bioreactor MFC: a separate compartment where organisms produce the hydrogen (fuel) and that hydrogen is fed into a hydrogen fuel cell.

2) Integrated bioreactor MFC: hydrogen fuel production and the electricity generation both take place in the same chamber.

3) MFC with mediated electron transfer: where intermediate molecules shuttle electrons from the microbial cell to the electrode.

4) MFC with direct electron transfer: where electron transfer to the electrode take place without the presence of any mediator molecules.

5) Mediator-less and membrane-less microfluidic MFC: an emerging type of MFC that eliminates use of mediators and cation exchange membrane.

The first two designs use hydrogen that is biologically generated and uses this hydrogen in a PEM-like fuel cell system. Thus, these fuel cells possess similarities with their inorganic counterparts. There are different types of bacteria and algae that generate hydrogen under anaerobic conditions, e.g. Escherichia Coli, Enterobactor and C. Butyricum that can be used in such reactors. Theoretical output in these fuel cells has been in the neighborhood of $10 \%$ but in actual environment, the values have been slightly less. Enzyme interactions (such as hydrogenases) with $\mathrm{H}_{2}$ is one reason for performance reduction. The inhibition of anaerobic hydrogenases by evolving oxygen (during 
photosynthesis) is another. Contamination of $\mathrm{H}_{2}$ with other gaseous species such as $\mathrm{CO}$ and $\mathrm{H}_{2} \mathrm{~S}$ is also considered to contribute toward inefficiencies. The second design mentioned above has similar disadvantages to the first with the only difference being the position of the bioreactor (Cooney, E, \& W, 1996; Scholz \& Schroder, 2003). Such MFCs commonly use Pt as electrode catalysts.

In the third type, an intermediate molecule known as mediator is used for electron transport (Tender et al., 2002). The mediator will shuttle electrons between the electrode and redox enzyme in the microorganism (Roller et al., 1984) following redox cycles as given in Equations $1 \& 2$. Different mediators that have been utilized in microbial fuel cell are listed in Figure A2.

$\mathrm{C}_{6} \mathrm{H}_{12} \mathrm{O}_{6}+$ Mediator $_{(\mathrm{o})} \longrightarrow$ Product + Mediator $(\mathrm{r})$

Mediator $_{(\mathrm{r})} \longrightarrow$ Mediator $_{(\mathrm{o})}+$ Electrons 


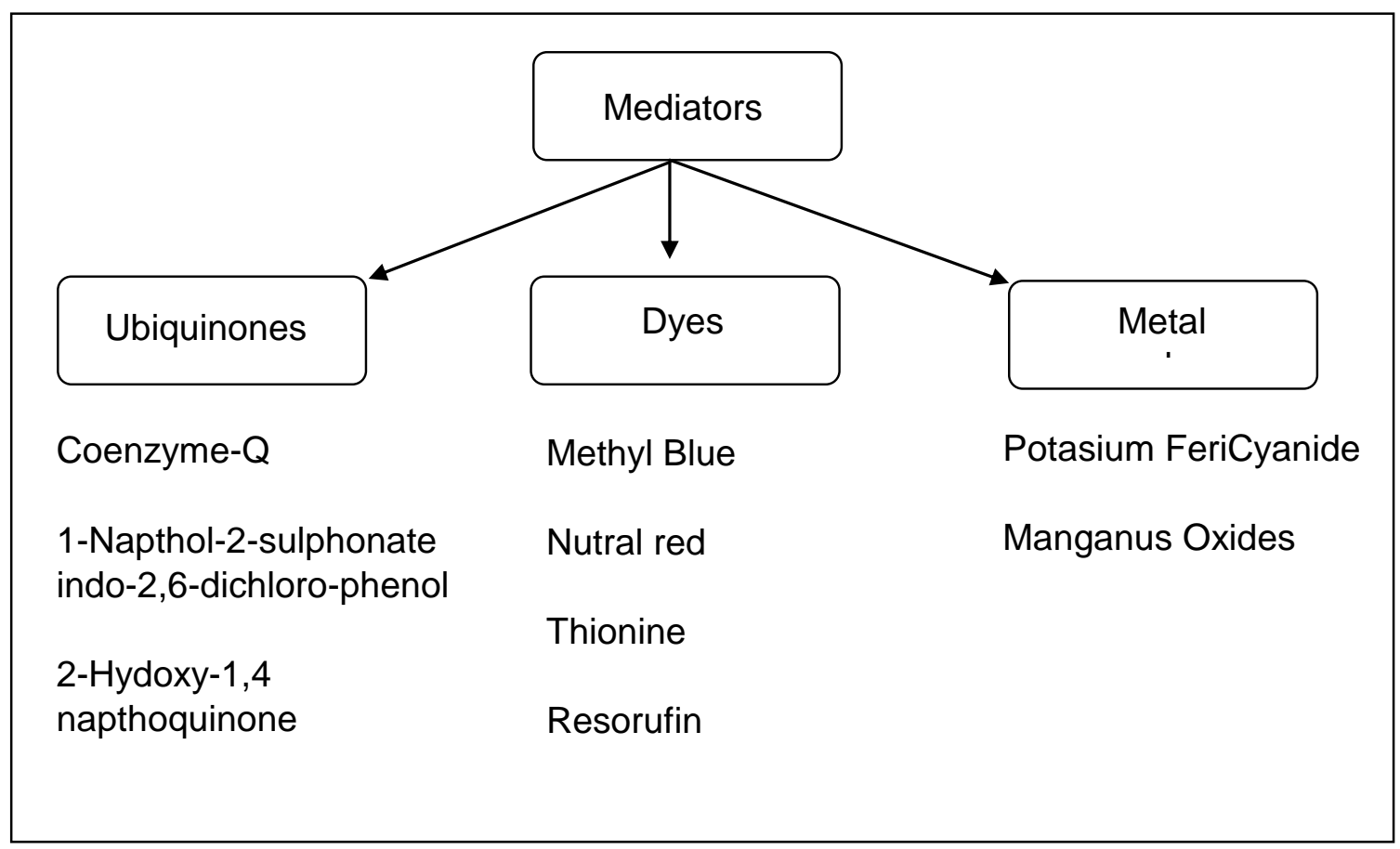

Figure A2. Different mediators used in biological fuel cells.

The characteristics that the mediators must possess are well established (Park \& Zeikus, 2003; I. Willner, KAtz, Patolsky, \& Buckmann, 1998): 1) The molecules should be able to form redox couples; 2) They should be stable in both, reduced and oxidized form; 3) They should not be biologically degradable; and 4) They should not be toxic to the biological species. However, in practice, mediators have commonly contributed to fuel cell performance issues due to degradation and toxicity to the biological medium (Delaney, 1984 ; Gil et al., 2003).

The fourth type of MFCs do not contain any extraneous mediators and in these fuel cells, bacteria are believed to communicate directly with the electrode using self-made 
mediators. Studies supporting this hypothesis have been conducted with iron-reducing bacteria such as Shewanella Putrefaciens, Geobactor Sulferreducens, Rhodeferax ferrireducens(Chaudhuri, 2003). The fifth type involves miniaturization of MFC using microfluidic technology which is capable of achieving high energy efficiency and durability. This type enables an advantage over conventional MFCs by eliminating the need for membranes (PEM) as a result of co-laminar flow of fuel and oxidant streams that extemporaneously separate anode and cathode in the cell. Electron transport to the anode can occur using electron mediators, or by direct membrane associated electron transfer, or by purported nanowires produced by certain microbes. (Fraiwan, Call, \& Choi, 2014; H.Y. Wang \& Su, 2013).

\section{Biochemical and Electrochemical phenomena that occur at the electrodes of} MFCs

Just like in any other fuel cell, the oxidation reaction in a microbial fuel cell occurs at the anode releasing electrons to and protons at the anode. The concomitant reduction half reaction takes place at the cathode collecting the electrons that travelled through an external circuit and combining them along with the protons with the terminal electron acceptor - which in most cases is oxygen. In order to keep the fuel from being crossed over to the cathode compartment or oxygen from entering the anode compartment (commonly referred to as cross over reactions), a membrane (commonly referred to as

proton exchange membrane or PEM) that is selective only for protons (transport) is 
generally used. A schematic of the reactions that take place in a microbial fuel cell is depicted in Figure A3.

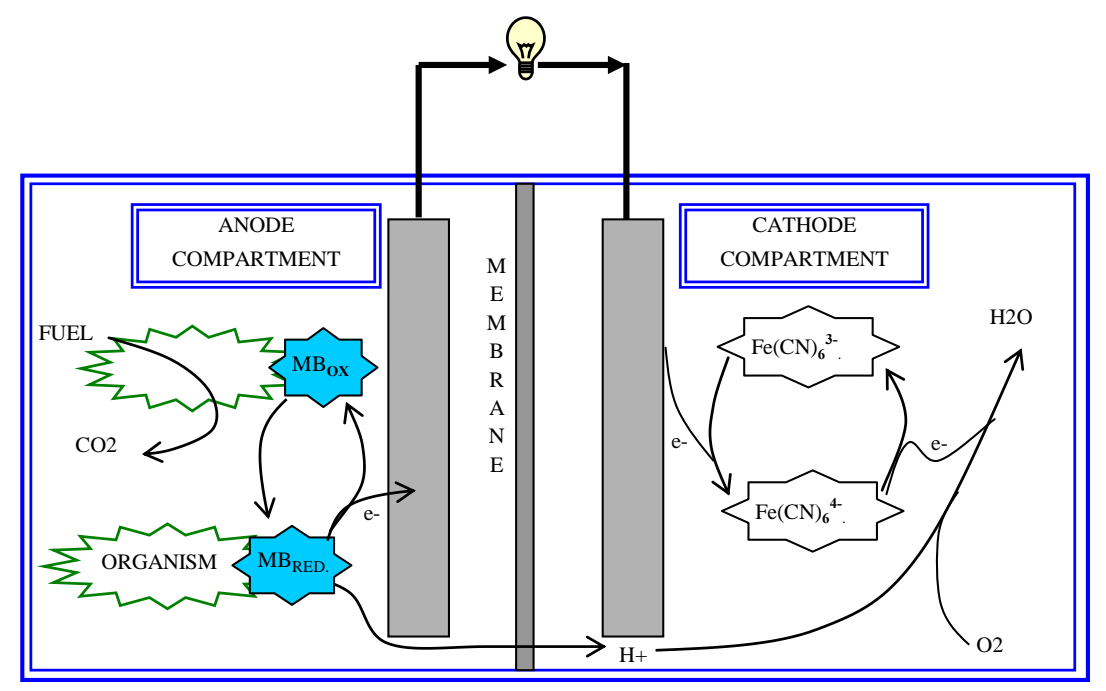

Figure A3. Schematic diagram of a microbial fuel cell and its operation (A. Gunawardena et al., 2008)

\subsection{Catabolic Pathways Involved in Energy Production from Microbes}

Microorganisms derive energy for living from the free energy produced by fuel oxidation. A part of the free energy produced is retained by the microbes for their catabolic activities and the rest may be utilized to generate electricity. Hence, for sustainable operation of the MFC, it is necessary for the microorganism to balance out the amount of energy consumed for its vitality and that being converted into electrical energy. 
There are two metabolic pathways used for energy conversion in microbes namely, respiration and fermentation. In the respiratory or oxidative pathway, the Gibbs free energy is utilized by the microbes for their respiration where the electrons circulate around a respiratory chain and finally exits the microbial cell via membrane-bound electron acceptors.

Under aerobic conditions, oxidation of the fuel glucose follows four distinctive steps (White, Handler, \& Smith, 1973): 1) Glycolysis, 2) Krebs Cycle, 3) Electron transport chain, and 4) Oxidative phosphorylation. In glycolysis which is also known as EmbdenMayarhoff-Parnas pathway, the six carbon glucose atom is broken down into two molecules of pyruvate as shown in Equation 3. This takes place in ten successive steps, each of which is catalyzed by a specific enzyme. Pyruvate, the product of glycolysis goes further through a three stage process where it is finally converted to $\mathrm{CO}_{2}$ and more energy in the form of ATP. The total ATP production from glucose in a respiring system is given in the Table 3.

$\mathrm{C}_{6} \mathrm{H}_{12} \mathrm{O}_{6}+2 \mathrm{NAD}^{+}+2 \mathrm{ADP}+2 \mathrm{Pi} \longrightarrow 2 \mathrm{NADH}+2 \mathrm{ATP}+2 \mathrm{Pyruvate}+2 \mathrm{H}^{+}+2 \mathrm{H}_{2} \mathrm{O}$ 
Table 3. ATP yield for corresponding biochemical reaction(s)

\begin{tabular}{|c|c|}
\hline Reaction Sequence & ATP Yield \\
\hline Glucose $\longrightarrow$ Fructose 1,6-diphoshate & -2 \\
\hline 2 Trios Phosphate $\longrightarrow$ & 2 \\
\hline$\longrightarrow 2 \mathrm{NADH} \longrightarrow 2 \mathrm{NAD}^{+}$ & 6 \\
\hline 2Phosphoenol pyruvic acid $\longrightarrow$ 2Pyruvic acid & 2 \\
\hline 2Pyruvic acid $\longrightarrow$ & \\
\hline $2 \mathrm{NAD}^{+} \longrightarrow 2 \mathrm{NADH} \longrightarrow \mathrm{2NAD}^{+}$ & 6 \\
\hline 2Acetyl CoA $\longrightarrow 4 \mathrm{CO}_{2}$ & 24 \\
\hline Net: $\mathrm{C}_{6} \mathrm{H}_{12} \mathrm{O}_{6}+6 \mathrm{O}_{2} \longrightarrow 6 \mathrm{CO}_{2}+6 \mathrm{H}_{2} \mathrm{O}$ & 38 \\
\hline
\end{tabular}

Even though aerobic respiration is the main form of energy generation in organisms, some can generate energy under anaerobic conditions. Under anaerobic conditions, glucose will be converted to pyruvate as it was under aerobic conditions, but in the next stage instead of the Krebs cycle a different pathway will follow - specific to the type of organism viz. prokaryote/eukaryote. While yeast for instance undergoes alcohol fermentation, some organisms follow the lactic acid fermentation.

In microbial catabolism under anaerobic conditions, carbohydrates are oxidized without the presence of oxygen. This oxidation reaction gets partially completed inside the microbial cellular structure and with the help of co-enzymes the electrons and protons are transferred outside the cellular membrane. The overall reaction of a fermentative MFC is given in Equation 4. This reaction can be broken down to half reactions as shown by Equation 5\&6. Inside the anaerobic compartment of a MFC, the reaction represented in Equation 4 takes place where the electrons released will be transferred to anode and the protons $\left(\mathrm{H}^{+}\right)$travel to the cathode compartment (sometimes via a proton exchange 
membrane). The released electrons from the anode will go through an external load as shown in Figure A3. and consequently enter the cathode.

$$
\begin{aligned}
& \mathrm{C}_{6} \mathrm{H}_{12} \mathrm{O}_{6}+6 \mathrm{O}_{2} \longrightarrow 6 \mathrm{CO}_{2}+6 \mathrm{H}_{2} \mathrm{O} \\
& \mathrm{C}_{6} \mathrm{H}_{12} \mathrm{O}_{6}+6 \mathrm{H}_{2} \mathrm{O} \longrightarrow 6 \mathrm{CO}_{2}+24 \mathrm{H}^{+}+24 \mathrm{e}^{-} \quad \mathbf{E}^{\mathbf{0}}=\mathbf{0 . 0 1 4 V} \\
& \mathrm{O}_{2}+24 \mathrm{H}^{+}+24 \mathrm{e}^{-} \longrightarrow 12 \mathrm{H}_{2} \mathrm{O} \quad \mathbf{E}^{\mathbf{0}}=\mathbf{1 . 2 3} \mathrm{V}
\end{aligned}
$$

Since ATP production is quite low under anaerobic conditions i.e. almost two molecules per one pyruvate molecule, the organisms need rapid processing of $\mathrm{NAD}^{+}$and $\mathrm{NADH}$. For the purpose of harvesting $\mathrm{H}^{+}$what matters for a MFC is the amount of co-enzyme $\left(\mathrm{NAD}^{+}\right)$getting involved in the reaction. In that perspective, anaerobic conditions are much favorable for the harvesting of protons when compared with aerobic conditions. Under anaerobic conditions, the rate of $\mathrm{NAD}^{+}$to $\mathrm{NADH}$ conversion takes place at a significant rate, while under aerobic conditions the already present oxygen in the media reacts with $\mathrm{H}^{+}$making it difficult to run the half reaction given by Equation 6 .

So, in a MFC system, the main electron acceptor that is engaged in harboring the electrons released from microbes is a solid anode. The formation of a biofilm on the anode is believed to be driven by the consumption of greater amounts of energy (released by microbial catabolism) by the solid anode when compared to the other electron acceptors. The bridging concepts of electron transfer between microbes and the solid anode is still under speculation and is discussed in brief in the next section. 


\subsection{Electron Transfer Mechanisms}

The electron transfer mechanism involves amalgamation of knowledge from electrochemistry, biochemistry and microbiology. Electrons pass on to the electrode of MFC as a result of several irreversible enzymatic reactions and eventually the reversible electrochemical reactions of the electron transport chain (Busalmen, Esteve-Nuñez, \& Feliu, 2008). For the reversible interfacial reaction to take place at the anode surface, electrons rely on shuttles such as cytochromes, proteins (such as PQQ), bound or soluble

redox mediators to reach at least within $10 \AA$ proximity of the anode (LaBelle \& Bond, 2009).

Several electron transfer mechanisms and processes have been proposed including direct electron transfer, indirect electron transfer and shuttle mediated transfer of electrons. Of the various mechanisms proposed, direct contact mechanism indicates formation of monolayer of microbes on the anode surface enabling direct transfer of electrons to the anode via cell membrane or a membrane organelle. Kim et al. (Kim et al., 2002) observed that certain Fe(III)-reducing bacteria (Shewanella putrefaciens) can transfer electrons to the electrode without the aid of synthetic mediators as shown in Figure A4(a). Cytochrome, a redox protein perhaps present on the outer membrane of the cell supposedly causes direct electron transfer by its electrochemical activity of reducing water soluble $\mathrm{Fe}(\mathrm{III})$. This type of transfer is capable of producing lowest extracellular potential losses due to the negligible gap between microbe and the electrode. However, the electron transfer in this mechanism is limited by the total number of bacteria in direct contact with 
anode. (Torres et al., 2010) Also, the c-type cytochrome may not be present in all the Fe(III)-reducing bacteria which further limits the electron transfer to a very few species (Lovley, Phillips, Lonergan, \& Widman, 1995).

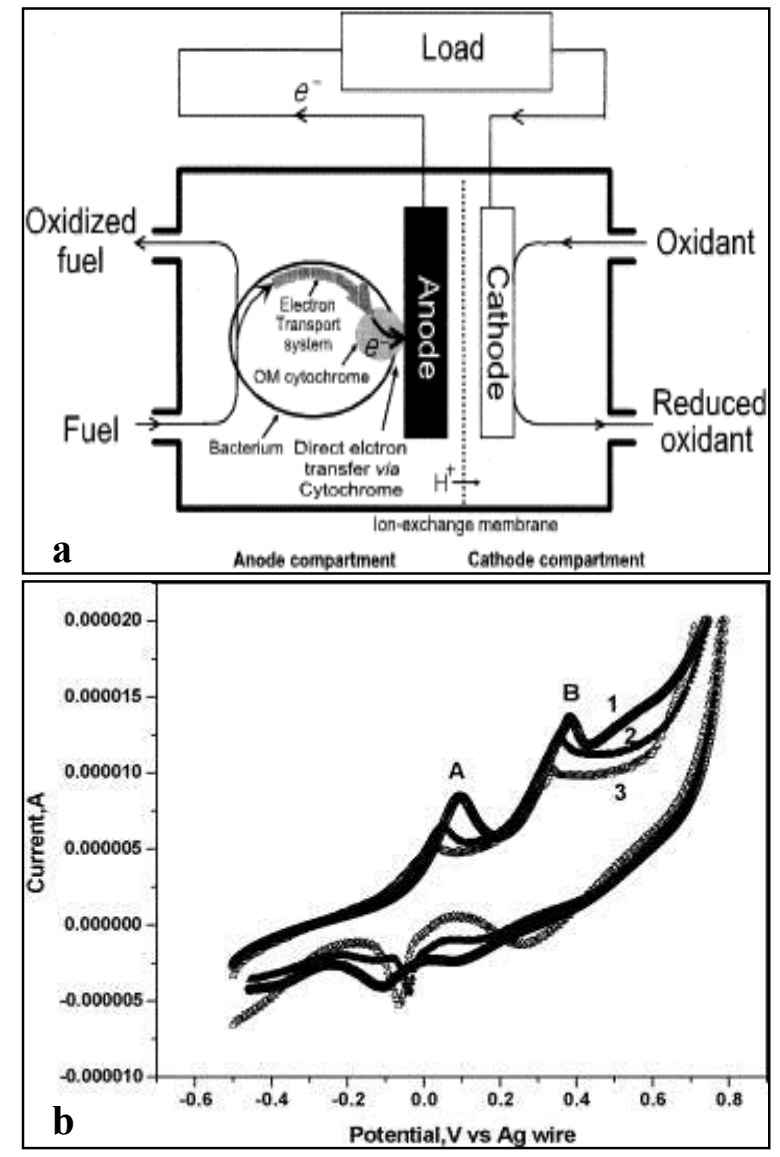

Figure A4. a) Schematic diagram describing direct electron transfer mechanism in MFC (Kim et al., 2002); b) CV of yeast biofilm on anode in phosphate buffer at scan rate 50 $\mathrm{mV} / \mathrm{s}$. (1) Blank CV; (2 and 3) after successive additions of $0.5 \mathrm{ml}$ each of lactate stock solution (Prasad et al., 2007).

Apart from ferric ion reducing bacteria, yeast cells (Hansenula anomala) have also been successfully found to enable a direct electrical communication between the cells and anode 
surface. In this case, electron transfer takes place without any external mediator or any intermediate redox reaction such as Fe(III) reduction, but with the help of redox enzymes, ferricyanide reductase and lactate dehydrogenase that are present on the outer membrane of the yeast cells. As can be seen in Figure A4(b), the CV reveals two redox peaks, A and $\mathrm{B}$ of the respective redox enzymes that are responsible for the electrochemical activity of the organism. These enzymes get reduced by consuming the electrons that are liberated during the oxidation of the substrate and transfer the electrons to the anode. The CV curves 2 and 3 depict reduction in peak currents upon subsequent addition of substrate indicating direct communication between the enzymes and anode (Prasad et al., 2007).

A recent discovery of interest in the milieu of direct electron transport (DET) mechanism in MFC is the pili growth seen in bacteria (Geobacter sulfurreducens). Pili also known as bacterial nanowires, are minute flexible structures made of protein called pillin that help the bacteria to cling to surfaces and distinguish materials in its surroundings. These pili overcome the limitation of the former mechanism by allowing charge transport through multiple layers of biofilms on the anode surface by not only being electrically conductive but also supposedly forming internal networks (see Figure A5). 


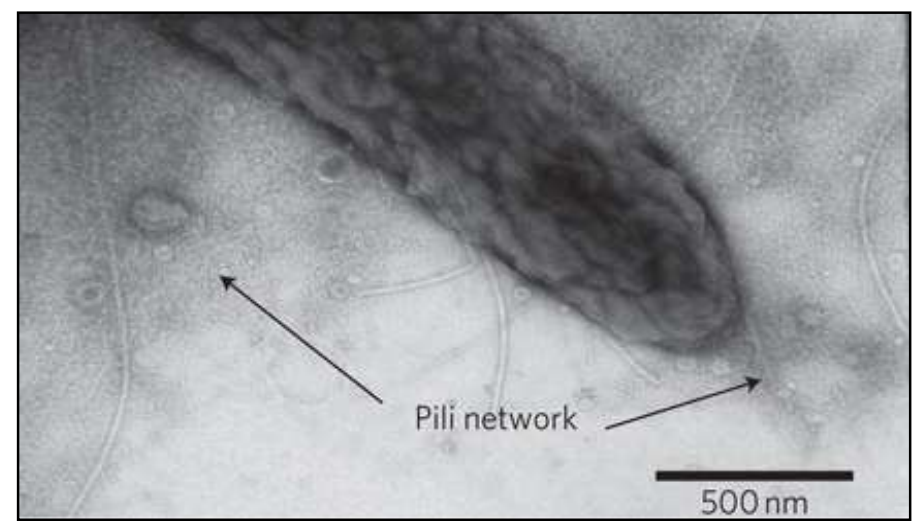

Figure A5. TEM image showing pili formed by the strain KN400 forming an interpenetrating network on the anode biofilm (Malvankar et al., 2011)

The subunit protein, PilA present in these pili consists of a cluster of aromatic acids that are believed to play a major role in its conductivity (Reardon \& Mueller, 2013; Reguera et al., 2005). Shewanella oneidensis uses both types of DET mechanisms involving c-type cytochrome and conductive pilus-like nanowires for electron transfer (Gorby et al., 2006; Lies et al., 2005). Conductivity of pili has may be measured using relation (7) given by Malvankar et al. (Malvankar et al., 2011)

$\sigma=G\left(\frac{2 a}{g L}\right)$

where $\mathrm{G}$ is the biofilm conductance, $\mathrm{L}$ is electrode length, $\mathrm{g}$ is thickness of biofilm and a is the non-conducting gap width between two working electrodes (anode).

Studies are ongoing to find if the amino acid sequences of PilA influence the conductivity of pili. While there have been positive findings on bacterial nanowires toward long-range 
electron transfer on anode; further in-depth investigations are required to find precisely what feature of the pili facilitates metal-like conductivity in pili and other microbial species that possess this trait (Malvankar \& Lovley, 2012).

Although direct contact mechanism is much sought after for electron transfer, extensive research on indirect or mediated electron transfer mechanism indicates that it is a conventional and efficient method for current generation in MFCs (U. Schröder, 2007). Indirect electron transfer mechanisms can be categorized based on the type of mediator used to wire the microbial catabolism with anode surface. A good mediator displays high membrane permeability, it is adequately soluble, possesses high electron transfer rate, non-toxic to microbial cells and non-biodegradable. In theory, mediators with low redox potentials (such as $\mathrm{SO}_{4}{ }^{2-}$ ) are said to be favorable for MFCs. This is because, electrons always flow from the low redox potential (of mediator) to the high redox potential (of electron acceptor or anode). However, mediators with high redox potentials have superior affinity for drawing electrons from the electron carriers in the cell.

Initially artificial redox mediators such as phenazines, phenothiazines, phenoxazines and quinones were used to carry out the electron transfer in the MFC systems. However, there are several disadvantages associated with these mediators that makes their use unsustainable and impractical - low current densities, difficulty in long range electron transfer over thick biofilms, need for regular addition of fresh mediators and toxicity. 
Hence, it was necessary to employ the intrinsic production of metabolites in microbes for electron transport purposes.

Microorganisms are capable of producing endogenous metabolites using primary and secondary pathways to carryout various biological processes. Primary metabolites such as $\mathrm{H}_{2}$ (Sekoai \& Gueguim Kana, 2014) and $\mathrm{H}_{2} \mathrm{~S}$ (Straub \& Schink, 2004) that are produced by microbial catabolic oxidation of fuel (anaerobic respiration and fermentation) have also been successfully used as redox mediators. Some secondary metabolites that have been considered for use in MFC applications are phenazine-1-carboxamide, pyocyanine (Pseudomonas aeruginosa)(Luo, Liu, Zhang, \& Cao, 2009), neutral red, anthraquinone2,6-disulfonate (AQDS), thionine, methyl viologen, methyl blue, humic acid (Thygesen, Poulsen, Min, Angelidaki, \& Thomsen, 2009) and 2-amino-3-carboxy-1,4naphthoquinone (ACNQ) (Bifidobacterium longum) (Yamazaki, Kano, Ikeda, Isawa, \& Kaneko, 1999). These mediators display cyclic redox behavior, which means that a single molecule can be used continuously for electron transfer to and fro the anode or biofilm. This is not only sustainable but also convenient for long range electron transfer in the anodic biofilms resulting in constant and enhanced generation of current.

\section{Factors that Affect Performance of Microbial Fuel Cells and Potential Remedies}

\subsection{Polarization losses}

Theoretically, MFC can attain a maximum cell voltage (emf) of $1.1 \mathrm{~V}$ under open circuit conditions. However, in reality it undergoes numerous forms of (polarization) losses and 
can achieve only $0.8 \mathrm{~V}$ (Liu, Cheng, \& Logan, 2004) in open circuit conditions and around 0.62 V (Rabaey, Clauwaert, Aelterman, \& Verstraete, 2005) during current generation. Overvoltage which is the difference between the theoretical and measured cell voltage collectively represents the overpotentials of the electrodes as wells as the overall ohmic loss of the system (Reguera et al., 2005). Prominent sources of these overpotentials are the intracellular and extracellular potential losses that occur in the biofilm formed on anode. When the internal resistance is high, there is a significant loss of charge in the system, thus reducing the effective voltage available at the end terminal (Barbir, 2005; Larminie, 2000). Key types of polarization losses (Figure A6) viz. activation polarization, concentration polarization, ohmic losses and losses due to microbial metabolic activities are discussed in more detail below. 


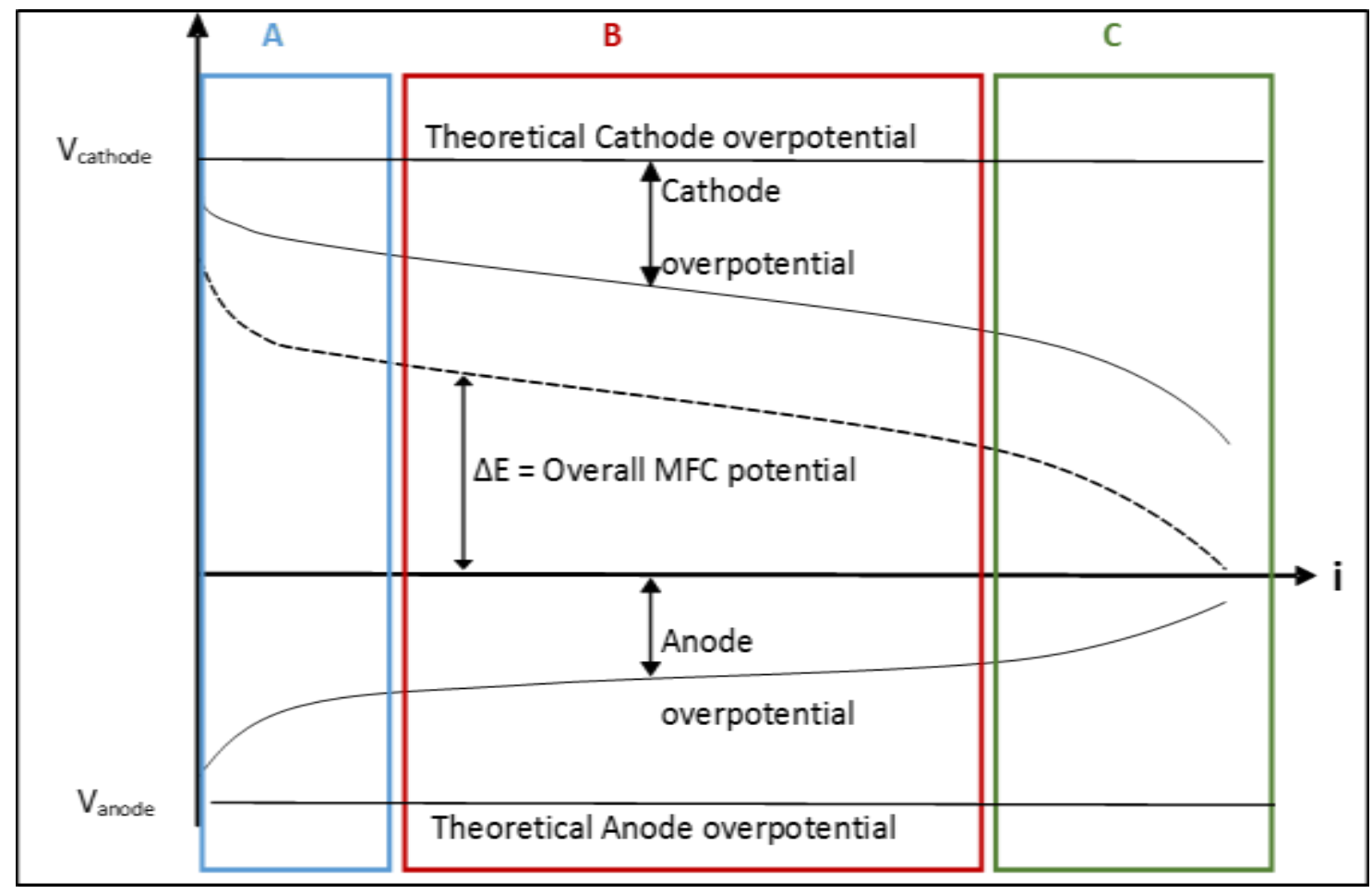

Figure A6. The polarization curve for a typical MFC

\section{Activation losses}

Usually, to initiate transport of charges liberated by fuel (electron donor) oxidation to the anode (electron acceptor), an energy barrier must be overcome. The energy barrier comprises of an additional potential known as activation overpotential that is required for transfer of electrons from fuel to microbial shuttles and finally to the anode. Activation losses, represented by region A in Figure A6. is observed as a sharp decrease in MFC voltage (low polarization) at the initial low current densities, but it is steadily overshadowed by ohmic and concentration losses which usually occur at intermediate or high current densities (region B in Figure A6). Clearly, activation losses occur at both anode and the cathode, and it is important to note that the cathodic overpotentials are much 
larger than anodic overpotentials. With the increased exchange current density this overpotential can be reduced (Barbir, 2005; Larminie, 2000). The activation losses can be explained from the Tafel equation shown by Equation 8 .

$\Delta \mathrm{V}_{\mathrm{act}}=\mathrm{A} . \times \log \left(\frac{i}{i_{o}}\right)$

where $\Delta \mathrm{V}_{\text {act }}$ : activation overpotential, A: Tafel Slope, $\mathrm{i}$ : current density, $\mathrm{i}_{\mathrm{o}}$ : exchange current density.

Some steps that can be taken to minimize the activation losses are:

\section{- Increasing anode surface area}

Increasing the surface area is a reliable approach to decrease the activation potential as when the surface area is increased the current density gets reduced. This can be done by increasing the electrode surface porosity and roughness.

\section{- Improving anode-microbe interactions}

In order to decrease the activation losses at the bacteria, it is necessary to improve anodemicrobe interactions. Using the correct mediator would eliminate this problem by enhancing electron transfer. As mediators would go inside the cell membrane it can reduce the intracellular activation losses as well. MFC systems employing microorganisms that produce conducting pili have relatively low activation polarization.

\section{- Increasing the operating temperature}


In an inorganic fuel cell raising the temperature would reduce the activation overpotential but in the microbial fuel cell or in the enzymatic fuel cell it is not possible to increase the temperature unless the bio-reaction section is separate from the anode chamber.

\section{- Decreasing the activation loss at the electrode surface}

The activation energy at the electrode surface can be decreased by adding catalyst to the electrode. The catalysts that has been widely tested is $\mathrm{Pt}$, which is reported to get polluted by bacterial suspensions. It has been reported that some success has been achieved by coating the electrode with a conducting layer that shield microbes from direct contact with the catalyst material (U. Schröder, Niessen, J. and Scholz, F. , 2003). Immobilization of catalysts such as neutral red (that also acts as a mediator) and manganese oxide on the electrode surface have shown to increase MFC power output. (Park \& Zeikus, 2003; Rhoads, Beyenal, \& Lewandowski, 2005)

The loss of potential due to internal current and crossover of reactants would also be significant if the fuel cell is operating at low current densities. Some electrons will pass through membrane rather than through the external circuit. The membrane is impermeable to the oxygen molecule but certain percentage can be diffused into the anode where it reduces the current that can pass through the external circuit.

\section{Ohmic losses}

Ohmic losses depicted as the medium polarization region B in Figure A6 is caused when the flow of charge is hindered as a result of the anodic resistance. The potential drop can 
be easily represented by ohms law as given in Equation 9 where $R_{i}$ represent the total internal resistance and $\mathrm{I}$ is the circuit current.

$\Delta V=I \times R i$

Increasing the conductivity of the anode material, minimizing contact resistance and the total travel distance of electrons within the anode helps in limiting the ohmic losses. Use of highly conductive anode materials with 3D architecture (eg. 3D graphite felt electrode) has shown to produce higher current generation by overcoming the ohmic losses (Aelterman, Versichele, Marzorati, Boon, \& Verstraete, 2008). The three dimensional structure not only offers a high surface to volume ratio but also an evident increase in the anode-microbe interaction, thus facilitating higher electron transport (Xie et al., 2010). Apart from this, resistance caused by the internal connections in the MFC system and the cation exchange membrane against the ionic flux also contributes to ohmic losses. The anodic (electrical) resistance were reported to be negligible when graphite electrodes were used (Barbir, 2005) and the contact resistance can also be significantly low as compared to the ionic resistance. Optimizing the electrode spacing, using a low resistance membrane while improving the conductivity and buffer capacity of the electrolyte (tolerable by the microorganism) are concomitant strategies to improve ion transfer through the membrane(B. E. Logan et al., 2006; Rozendal, Hamelers, Rabaey, Keller, \& Buisman, 2008). 


\section{Concentration losses}

Imbalance in rate of mass transfer of substrate and products to and from the anode respectively and the total current generated in the system may result in increase in anode potential and decrease in cathode potential or vice versa causing concentration (or mass transport) losses. These losses are most prominent at high current densities due to diffusion-limited mass transfer of the fuel to the anode surface. Also, the accumulation of oxidized products and cations in the biofilm may change the redox conditions and alter the metabolic activities of the microbes. Hindrance in cation transport may further cause a $\mathrm{pH}$ gradient between the electrodes leading to a significant reduction in the power output. Anode design and operational parameters are contributing factors toward concentration losses represented by the maximum polarization region $\mathrm{C}$ in Figure A6.

\section{Losses due to fuel scavenging metabolic processes of microrganisms}

Loss of voltage can also occur due to catabolic activities of the microbe while deriving energy from fuel oxidation. As discussed earlier in the chapter, in an effective MFC, the anode potential should be as low as possible to allow attainment of high MFC voltage and adequate catabolic energy gain for the survival of microorganisms. Nevertheless, extremely low anode potential can hinder electron transfer causing fermentation of fuel while producing high energy products, resulting in loss of electrons. Furthermore, this also leads to added electron losses by excessive buildup of anodophilic biomass. A number of factors such as type of microbes, community composition, anode-microbe interaction, rate of fuel degradation by the microbes, number of microbes actively degrading the fuel and 
mix up of fuel through the electrolyte between the electrodes can affect the microbial metabolic losses.

\subsection{Microbial Interaction with the Anode Surface}

The electrical performance of a MFC is largely dependent on how well the microorganisms interact with the anode. A prime requirement here is that the biofilm that comprise of the microbes is adhered properly onto the anode.

Microbial adhesion on anode surface can be understood by the notion of surface charges. Most of the micro-organisms are negatively charged by nature and hence, attract positively charged surfaces. So, several (surface) modification techniques have been employed to facilitate this charge attraction process. For example, treating the anode surface with ammonia has been successfully attempted. Ammonia treatment facilitates the negatively charged bacteria to readily attach to the now positively charged anodes. The power output of the treated anode was expectedly much higher than its non-treated counterpart. However, high temperature requirements and, complex conditions and instrumentation have made this process commercially less feasible. In a different instance, treatment of activated carbon felt anodes with nitric acid (acid treatment) for rendering positively charged surfaces has resulted in a 58\% increase in power density (N. Zhu et al., 2011). Zhou et al. reported that electrochemical oxidation of anode led to the change of the anode properties, such as augmented surface area, reduced internal resistance and anode 
potential, and therefore aided to the microbial adhesion and electron transfer on the anode surface (Zhou, Chi, Wang, \& Jin, 2012).

\section{Role of Anode Material and Architecture}

Anode material and its architecture directly affects microbial adhesion, electron transfer and fuel oxidation. The noble metal electrodes ( $\mathrm{Pt}, \mathrm{Au}, \mathrm{Ag}, \mathrm{Pd})$ have reported to be less attractive as MFC anodes due to high cost and weak adhesion of microbes; and other highperforming electrodes $(\mathrm{Ni}, \mathrm{Cu}, \mathrm{Rh}, \mathrm{Ir}$ ) have been sought as alternatives (kumar, Sarathi, \& Nahm, 2013).

Carbon-based anodes have been extensively tested for MFC applications as they exhibit superlative properties such as high conductivity, durability, eco-friendliness and their flexibility to be shaped into various architectures. They can have planar, packed or brush like configuration(s). The conventional electrodes include graphite rod, felt, plate and fiber brush, carbon felt, cloth and paper, and reticulated vitreous carbon (RVC) (B. Logan, Cheng, Watson, \& Estadt, 2007; Vargas, Albert, \& Regan, 2013). Logan et al. made an observation that packed and brush design of anodes gave higher power output than the planar type anodes by increasing the anode specific surface area and consequently the volumetric density of exoelectrogenic bacteria (B. Logan et al., 2007). Additionally, the brush configuration also has high porosity. The fibrils of the brush anode helps the microorganisms to hold onto the anode structure. Due to its enhanced conductivity and non- 
corrosive nature, titanium was found to be a suitable core wire on which the carbon or graphite fibers are wound.

Lately, nanomaterials have attracted much attention in various fields due to their unusual yet beneficial structural, chemical and electrical properties. Use of nanomaterial for anodes and electron transport has been reported to augment the performance of MFCs. Fan et al. showed that $\mathrm{Au}$ and Pd nanoparticle decorated anodes produced enhanced current densities than that of the control electrodes. They also observed that the anodic performance was significantly affected by not only the chemical composition of nanoparticles but also their size and shape (Fan et al., 2011). In 2012, Xu et al. tested Fe nanoparticle-decorated graphite disks which resulted in approximately six-fold higher average current densities than the plain graphite anode. Upon running a whole genome microarray analysis of the gene expression of Shewanella oneidensis used in this study, they found out that genes encoding biofilm formation were significantly up-regulated as a response to nanoparticle-decoration (Xu et al., 2012). However, it should also be noted that the probable cytotoxicity of certain nanoparticles often limit the possibilities that can be reached using nano- materials for MFC applications.

Coating the anode surface with materials such as carbon nanotubes (CNTs), conductive polymers and nanopolymer composites are other methods used for anode surface modification. Conductive polymer based anodes utilizing polypyrrole (Feng, Li, Liu, Lang, \& Fan, 2010), poly(3-hydroxy butyrate-co-3-hydroxyvalerate) (Luckarift et al., 
2012), nanowire networks (Zhao, Nakanishi, Watanabe, \& Hashimoto, 2011) and nano/composites of the polymers (Higgins et al., 2011; Kalathil et al., 2013; Yuan \& Kim, 2008) have been studied and found to significantly increase MFC performance.

Recent studies show that CNTs are promising electrode materials due their high surface area, superior electrical conductivity, chemical inertness, decreased startup time and low internal resistance (Liang et al., 2011). Functionalizing the CNTs appropriately, may further enhance electron transport. Mink et al. (Mink, Rojas, Logan, \& Hussain, 2012) made observations on a forest type multi-walled carbon nanotubes (MWCNTs) with a nickel silicide contact area that produced current density of $197 \mathrm{~mA} / \mathrm{m}^{2}$ and power density of $392 \mathrm{~mW} / \mathrm{m}^{3}$. MWCNTs were said to have increased the anode surface-to-volume ratio, which improved the ability of the microbes to couple and transfer electrons to the anode. Nickel silicide reported to boost the output current by providing a low resistance contact area that allowed efficient shuttling of electrons.

A three dimensional architecture that facilitates augmented growth of the microbes can be achieved by embedding CNTs on carbon cloth and polyester fabric using doping techniques. Also, the CNT coating stimulates active surface interactions with the microbes enabling direct electron transfer thereby giving $68 \%$ high power density and 10 -fold-lower charge-transfer resistance than the traditional carbon cloth based anodes (Xie et al., 2010). Yet another advancement in the three dimensional anodes was the 3D conducting graphene-polyaniline framework that was reported to outperform the planar carbon 
electrode by additionally providing multiplexed and highly conductive pathways (Yong, Dong, Chan-Park, Song, \& Chen, 2012). Wang et al. (H. Wang et al., 2013) developed a 3D reduced graphene oxide-nickel foam as an anode for MFC achieved a remarkable volumetric power density of $661 \mathrm{~W} / \mathrm{m}^{3}$ based on the volume of the anode, which is the highest value yet obtained for a MFCs with a pure strain of S. oneidensis MR-1.

\section{Conclusion}

In summary, MFCs have tremendous potential to generate electrical energy from chemical energy present in organic fuels primarily for decentralized stationary power generation applications. However, challenges associated with effective mass and charge transport along with the intricacies associated with making the living organisms interact with the inorganic (electrode) world have hampered this technology coming to technological fruition as yet. Advances in material science coupled with nanotechnology may provide novel tools to effectively harvest, transport and utilize electrical charges generated by MFCs for useful applications in the forthcoming future. 